\title{
ESTIMATION OE REGULATORY CREDIT RISK MODELS
}

\section{3}

Carlos Perez Montes.

Documentos de Trabajo. N. 1305

\section{banco es españa}

\author{
Eurosistema
}


ESTIMATION OF REGULATORY CREDIT RISK MODELS 
ESTIMATION OF REGULATORY CREDIT RISK MODELS

Carlos Pérez Montes ${ }^{(*)}$

BANCO DE ESPAÑA

${ }^{*}$ ) Carlos Pérez Montes belongs to the Department of Financial Stability at the Directorate General of Regulation and Financial Stability. The author would like to thank Javier Mencía, Jesús Saurina and Carlos Trucharte for the comments received on this project.

Documentos de Trabajo. N. ${ }^{\circ} 1305$ 
The Working Paper Series seeks to disseminate original research in economics and finance. All papers have been anonymously refereed. By publishing these papers, the Banco de España aims to contribute to economic analysis and, in particular, to knowledge of the Spanish economy and its international environment.

The opinions and analyses in the Working Paper Series are the responsibility of the authors and, therefore, do not necessarily coincide with those of the Banco de España or the Eurosystem.

The Banco de España disseminates its main reports and most of its publications via the INTERNET at the following website: http://www.bde.es.

Reproduction for educational and non-commercial purposes is permitted provided that the source is acknowledged.

C BANCO DE ESPAÑA, Madrid, 2013

ISSN: 1579-8666 (on line) 


\section{Abstract}

This article estimates a general credit risk model with both macroeconomic and latent credit factors for Spanish banks during the period 2004-2010. The proposed framework allows to estimate with bank level data both the standard credit risk model of Basel II and generalized models. I find evidence of persistence in the credit latent factor and of a significant effect of GDP growth and interbank rates on loan default rates. The estimated default correlation is low across specifications. The model is also used to calculate the impact on the probabilities of default of stressed economic scenarios.

Keywords: credit risk, default correlation, stress test, state space model, bootstrap, MLE.

JEL classification: E0, G21. 


\section{Resumen}

Este artículo estima un modelo general de riesgo de crédito que incluye tanto factores macroeconómicos como factores de crédito latentes para los bancos españoles durante el período 2004-2010. El marco propuesto permite la estimación con datos de bancos individuales tanto del modelo de crédito estándar de Basilea II como de modelos más generales. Se encuentra evidencia de un factor de crédito latente persistente y de un efecto significativo del crecimiento del PIB y de los tipos de préstamo interbancarios en la tasa de impago. La estimación de la correlación entre impagos es baja para las distintas especificaciones, lo que indica una relación positiva entre concentración bancaria y estabilidad financiera. Se utiliza el modelo para calcular el impacto en las probabilidades de impago de distintos escenarios económicos estresados.

Palabras clave: riesgo de crédito, correlación de impagos, test de estrés, modelo de espacio de estados, bootstrap, estimación por máxima verosimilitud.

Códigos JEL: E0, G21. 


\section{Introduction}

The correct modeling of the factors determining credit default is crucial to ascertain the stability of a financial system, as recognized in the international regulatory framework of Basel II. ${ }^{1}$ This article estimates a model of credit default with bank level data that allows to separate the effects of system-wide variables, macroeconomic shocks and common latent factors, and individual bank characteristics and loan rate policies. The risk model of Vasicek (2002) with an independent single risk factor provides the basis for the evaluation of credit risk and capital requirements in the framework of Basel II. ${ }^{2}$ The framework in this article can be used to estimate the model of Vasicek (2002), and it can also incorporate autocorrelation in the risk factor and multiple risk factors. Additionally, the use of bank level data allows to estimate default rates for each institution rather than using only aggregate estimates for different credit portfolios -loans to non financial firms, mortgages and personal loans. The control for individual bank characteristics can also produce more precise estimates of the correlation of default events across individual loans.

I estimate the latent factor model with the quasi maximum likelihood method, QML henceforth, applied to a panel of representative Spanish banks for every quarter during the period January 2004-June 2010. The use of the Kalman filter and the state space representation of the default processes allows me to introduce latent factors, with either i.i.d. or AR(1) dynamics, and exogenous explanatory variables such as GDP growth and interbank rates that extend the standard credit model of Basel II. The autoregressive dynamics and the impact of the macroeconomic variables is found to be significant, pointing to the advantages of generalizing the standard credit model. Furthermore, the impact of latent factors and the correlation of default across loans are estimated to be lower when these generalizations are incorporated into the model. On the other hand, the shift to a two-factor model does not seem to have an important impact on estimated correlation.

\footnotetext{
${ }^{1}$ I refer throughout the document to the regulatory structure for International Convergence of Capital Measurement and Capital Standards of the Basel Committee of Banking Supervision (2004) as Basel II.

${ }^{2}$ See also Gordy (2003) for an analysis of the application of Vasicek (2002) to internal ratings models.
} 
The credit model is not only useful to form estimates of default rates at a given point in time, but also to evaluate the sensitivity of financial stability to changes in the structure of the financial system. There has been recent theoretical interest in the effects of competition on the probability of bank failure. Boyd and De Nicolo (2005) introduce a credit model with borrower moral hazard in the tradition of Stiglitz and Weiss (1981) in which more intense bank competition reduces the probability of bank failure. In this model, the lower loan rates with more bank competition induce borrowers to behave more prudently and induce lower default rates. Martinez-Miera and Repullo (2010) show that the results in Boyd and De Nicolo (2005) rely on the assumption of perfect correlation of defaults. This latter article also shows that, with the credit risk model of Vasicek (2002), the relation between competition and bank failure is a function of the correlation of defaults. ${ }^{3}$ The current article can provide estimates of the credit risk correlation parameter in the credit model of Vasicek (2002), and in more general credit risk models, and provides a basis to form an empirical evaluation of the effect of competition on financial stability based on the theory models above. ${ }^{4}$

From a regulatory perspective, this article presents a flexible framework that allows to perform stress tests for individual institutions and for system-wide credit portfolios of business loans, mortgages and personal loans. The model includes GDP growth and the interbank rate as explanatory variables and it is possible to study the sensitivity of default rates to adverse macroeconomic conditions. Moreover, the inclusion of latent credit factors allows to stress the credit portfolio with negative realizations of these unobserved factors. The estimation of the model with the actual credit performance data of the banks and, particularly, the performance of retail mortgages and personal loans, potentially improves the precision of the stress test exercise with respect to credit models that rely on market data of defaults of corporate portfolios.

The credit performance of the Spanish financial system has been studied in a number of articles. The current work is closest to Jimenez and Mencia (2009), who estimate a model with macroeconomic and latent factors for default rates and credit exposures at the industry sector

\footnotetext{
${ }^{3}$ The relation between competition and bank risk taking has been also studied in Chiappori et al. (1995), Hellmann et al.(2000), Matutes and Vives (2000) and Repullo (2004).

${ }^{4}$ Acharya (2009) evaluates bank closure policy and capital requirements in a duopoly model in which banks choose credit correlation. The credit risk model differs from the framework in this article, but it is still an additional example of the importance of credit correlation for prudential regulation.
} 
level -agriculture, manufacturing, mortgages, etc. Jimenez and Mencia (2009) contribute to this literature with the introduction of unobserved latent factors in a model of credit risk with loan data and find that the persistency of latent factors affects the distribution of default rates. Jimenez and Saurina (2006) find evidence of a lagged positive relation between credit growth and credit losses in the Spanish banking sector. Jimenez, Salas and Saurina (2006) focus on financial loans to firms and study the determinants of the use of collateral and the relation of these guarantees and credit risk. Jimenez, Lopez and Saurina (2009) study the relation between the use of credit lines and the borrower credit performance. Rodriguez and Trucharte (2007) estimate a logistic model of credit default for the mortgage portfolio and apply it to perform a stress test with a non-parametric approach. The current article uses data at the bank level of loans to both non financial firms and households and it incorporates the effect of individual bank characteristics on credit performance.

There is an scarcity of articles that estimate the parameters in the credit risk model in Basel II from loan default data. Kupiec (2009) introduces a fixed effect linear estimator for the credit parameters of the Basel II credit framework and he considers the effect on estimation bias of autocorrelation in the single credit factor. Following Kupiec (2009), I estimate directly the credit model parameters, but I use the Kalman filter to control for possibly autocorrelated common latent factors rather than using fixed time effects. As in Jimenez and Mencia (2009), I use data on loan defaults, whereas Kupiec (2009) uses data on the defaults of corporate bonds. ${ }^{5}$ Differently from Jimenez and Mencia (2009), I use bank level portfolios rather than aggregate industry portfolios and I study explicitly the standard Basel II credit model. Alternative approaches that calibrate the correlation parameter of Basel II from stock return data, e.g., Lopez (2004), are limited to use the exposures of listed companies.

The article is organized as follows. Section 2 presents the formal model of default behaviour. Section 3 describes the dataset and provides preliminary descriptive analysis. Section 4 details the estimation methodology. Section 5 presents the main results and analyzes the sensitivity of default to macroeconomic variables and bank loan rates. Section 6 concludes.

\footnotetext{
${ }^{5}$ The defaults of corporate U.S bonds have been thoroughly analyzed. Recently, Duffie at al. (2009) find that the addition of a second factor in a continuous-time latent factor model is necessary to control for correlation in corporate bond defaults.
} 


\section{Model}

\subsection{Model of Default Behaviour}

The event of default at date $t$ of a borrower $i$ in a loan contract of risk class $r$ that was granted by a bank $j$ is driven by observed macroeconomic and bank-specific variables and unobserved latent factors. The observed variables include the time-invariant effects of bank organization $f_{j}$ and the risk class of the loan contract $f_{r}$, the bank level average loan rate $r_{j r t-s}$ at date $t-s$, with $s>0$, and the macroeconomic factors in the $(M \times 1)$ vector $M_{t}$. Unobserved factors include $L$ time-variant common latent factors $\xi_{t}$ and an idiosyncratic random component $\varepsilon_{i j r t}$. The default happens if the latent random variable $d_{i j r t}$ takes a value such that $d_{i j r t}<0$, where $d_{i j r t}$ is defined as:

$$
d_{i j r t}=f_{j}+f_{r}+\gamma \cdot r_{j r t-s}+\rho_{M} \cdot M_{t}+\rho_{\xi, r} \cdot \xi_{t}+\rho_{\varepsilon} \cdot \varepsilon_{i j r t}
$$

where $\rho_{M}$ and $\rho_{\xi, r}$ are respectively $(1 \times M)$ and $(1 \times L)$ vectors of coefficients and $\left\{\gamma, \rho_{\varepsilon}\right\}$ are real scalars. The random variables $\xi_{t}$ and $\varepsilon_{i j r t}$ are independently distributed. The idiosyncratic components $\varepsilon_{i j r t}$ are standard normal i.i.d. across borrowers, banks, risk classes and time. The time-variant common latent factors $\xi_{t}$ are assumed to follow a first order covariance-stationary process with a conditional normal distribution:

$$
\xi_{t+1}=F \cdot \xi_{t}+v_{t}
$$

where $F$ is a $(L \times L)$ matrix of coefficients for the first-order dynamics and $v_{t}$ is a random vector with normal distribution $N\left(0, \Sigma_{v}\right)$, where $\Sigma_{v}$ is a $(L \times L)$ variance-covariance matrix.

The probability of default $\operatorname{Pr}\left(d_{i j r t}<0 \mid \iota_{t}\right)$ of a borrower $i$ in risk class $r$ and bank $j$ conditional on the non-idiosyncratic factors in $\left(f_{j}, f_{r}, r_{j r t-s}, M_{t}, \xi_{t}\right)$ is given by:

$$
\operatorname{Pr}\left(d_{i j r t}<0 \mid \iota_{t}\right)=\Phi\left(\frac{-\left(f_{j}+f_{r}\right)}{\rho_{\varepsilon}}-\frac{\gamma}{\rho_{\varepsilon}} \cdot r_{j r t-s}-\frac{\rho_{M}}{\rho_{\varepsilon}} \cdot M_{t}-\frac{\rho_{\xi, r}}{\rho_{\varepsilon}} \cdot \xi_{t}\right)
$$


where $\iota_{t}$ indicates knowledge of the set of conditioning variables $\left(f_{j}, f_{r}, r_{j r t-s}, M_{t}, \xi_{t}\right)$ at time $t$ and $\Phi$ is the standard normal cumulative distribution function, c.d.f. henceforth. It is therefore possible to write the probability of default transformed by the inverse of the normal c.d.f. as a linear function of the factors $\left(f_{j}, f_{r}, r_{j r t-s}, M_{t}, \xi_{t}\right)$ :

$$
y_{j r t}^{*}=f_{j}^{*}+f_{r}^{*}+\gamma^{*} \cdot r_{j r t-s}+\rho_{M}^{*} \cdot M_{t}+\rho_{\xi, r}^{*} \cdot \xi_{t}
$$

where $y_{j r t}^{*}$ denotes the transformed probability $\Phi^{-1}\left(\operatorname{Pr}\left(d_{i j r t}<0 \mid \iota_{t}\right)\right), f_{j}^{*}=-f_{j} / \rho_{\varepsilon}, f_{r}^{*}=-f_{r} / \rho_{\varepsilon}$, $\gamma^{*}=-\gamma / \rho_{\varepsilon}, \rho_{M}^{*}=-\rho_{M} / \rho_{\varepsilon}$ and $\rho_{\xi, r}^{*}=-\rho_{\xi, r} / \rho_{\varepsilon}$.

\subsection{Empirical Specification}

The default rates transformed by the inverse operator $\Phi^{-1}()$ can be collected into a $(J \cdot 4 \times 1)$ vector $y_{t}^{*}$, where $J$ is the number of banks in the sample and 4 is the number of risk classes: loans to non financial firms (NFFs henceforth) with notional amount above 1 million euros $(r=1)$, loans to NFFs with notional amount below 1 million euros $(r=2)$, mortgages $(r=3)$ and personal loans $(r=4)$. The time-invariant fixed effects for bank and risk class are also collected into a $(J \cdot 4 \times 1)$ vector $f^{*} \equiv\left(f_{11}^{*}, f_{12}^{*}, f_{13}^{*}, f_{14}^{*}, \ldots, f_{j r}^{*}, \ldots, f_{J 4}^{*}\right)^{T}$, with the entry for bank $j$ and risk class $r$ equal to $f_{j r}^{*}=f_{j}^{*}+f_{r}^{*}$. The lagged loan rates are also collected into $(J \cdot 4 \times 1)$ vector $r_{t-s} \equiv\left(r_{11 t-s}, r_{12 t-s}, r_{13 t-s}, r_{14 t-s}, \ldots, r_{j r t-s}, \ldots, r_{J 4 t-s}\right)^{T}$. The model in $(2)$ can then be expressed at each time $t$ as a vector equation:

$$
y_{t}^{*}=f^{*}+\gamma^{*} \cdot r_{t-s}+\beta_{M} \cdot M_{t}+\beta_{\xi} \cdot \xi_{t}
$$

where $\beta_{M}$ and $\beta_{\xi}$ are respectively $(J \cdot 4 \times M)$ and $(J \cdot 4 \times L)$ matrices that stack vertically copies of $\rho_{M}^{*}$ and $\rho_{\xi, r}^{*}$. More precisely,

$$
\beta_{M}=1_{J \cdot 4} \otimes \rho_{M}^{*} ; \quad \beta_{\xi}=1_{J} \otimes\left[\begin{array}{c}
\rho_{\xi, 1}^{*} \\
\rho_{\xi, 2}^{*} \\
\rho_{\xi, 3}^{*} \\
\rho_{\xi, 4}^{*}
\end{array}\right]
$$


where $1_{J \cdot 4}$ and $1_{J}$ are column vectors of ones with dimensions $(J \cdot 4 \times 1)$ and $(J \times 1)$, and $\otimes$ denotes the Kronecker product.

In order to obtain a default model that can be estimated, I introduce assumptions on the distribution of measurement error as in Kupiec (2009). In particular, I assume that the observed transformed default rates $y_{t}$ are equal to the sum of the model prediction $y_{t}^{*}$ and a $(J \cdot 4 \times 1)$ vector of measurement errors $\eta_{t}$, i. e., $y_{t}=y_{t}^{*}+\eta_{t}$. The terms in vector $\eta_{t}$ are distributed as independent normal variables with homoscedastic variance covariance $\Sigma_{\eta}$. In particular, the vector $\eta_{t}$ is independent of the latent credit risk factors $\xi_{t}$. The state-space representation of the default model is then:

$$
\begin{aligned}
y_{t} & =f^{*}+\gamma^{*} \cdot r_{t-s}+\beta_{M} \cdot M_{t}+\beta_{\xi} \cdot \xi_{t}+\eta_{t} \\
\xi_{t+1} & =F \cdot \xi_{t}+v_{t} \\
\eta_{t} & \sim N\left(0, \Sigma_{\eta}\right), v_{t} \sim N\left(0, \Sigma_{v}\right)
\end{aligned}
$$

This general model can be adapted to the standard credit risk framework in Basel II regulation and it can also be used to estimate specifications with correlation across time in the common latent factor and multiple latent factors. I detail next the main specifications used in the article.

\subsubsection{Basel II Single Factor Default Risk Model}

The model in Vasicek (2002) contains a single common latent factor $\xi_{t}$, which is distributed as a standard normal random variable and it is i.i.d. across time. In the model in (3), the restrictions $F=0$ and $\Sigma_{v}=\sigma_{v}=1$ are necessary to obtain the single factor model of Vasicek (2002). Additionally, the model restricts the variables $\xi_{t}$ and $\varepsilon_{i j r t}$ to mix into a standard normal variable, $\rho_{\varepsilon}=\sqrt{1-\rho}$ and $\rho_{\xi, r}=\sqrt{\rho}$ for all risk classes $r$ with $\rho \in(0,1)$. This simple structure 
implies that the correlation between two default events is $\rho$. In this model, the probability of default in risk class $r$ for bank $j$ with no information on $\xi_{t}$ is:

$$
\operatorname{Pr}\left(d_{i j r t}<0 \mid \iota_{t-1}\right)=\Phi\left(-f_{j}-f_{r}-\gamma \cdot r_{j r t-s}-\rho_{M} \cdot M_{t}\right)
$$

where $\iota_{t-1} \equiv\left(f_{j}, f_{r}, r_{j r t-s}, M_{t}, \xi_{t-1}\right)$. The i.i.d. assumption on the common latent factor implies that knowledge of $\xi_{t-1}$ brings no information about $\xi_{t}$, and $\operatorname{Pr}\left(d_{i j r t}<0 \mid \iota_{t-1}\right)$ is conditioned only on the fixed-effects, loan rate $r_{j r t-s}$ and macroeconomic factors in equation (4).

\subsubsection{Single Factor Default Risk Model with Autocorrelation}

It is straightforward to modify the model in Vasicek (2002) to allow for serial correlation in the common latent factor. In the model (3), a single common latent factor $\xi_{t}$ with an $\operatorname{AR}(1)$ process requires the restrictions $F \in(-1,1)$ and $\Sigma_{v}=\sigma_{v}=1$. This specification still restricts the variables of $\xi_{t}$ and $\varepsilon_{i j r t}$ to mix into a normal variable, $\rho_{\varepsilon}=\sqrt{1-\rho}$ and $\rho_{\xi, r}=\sqrt{\rho}$ for all risk classes $r$ with $\rho \in(0,1)$, as in the credit risk model of Vasicek (2002). The $A R(1)$ process of $\xi_{t}$ implies that the expectation of latent factors condtional on $\iota_{t-1}$ is $E\left[\sqrt{\rho} \xi_{t}+\sqrt{1-\rho} \varepsilon_{i j r t} \mid \iota_{t-1}\right]=\sqrt{\rho} \cdot F \cdot \xi_{t-1}$ rather than the unconditional zero expectation. The probability of default with no information on $\xi_{t}$ is then:

$$
\operatorname{Pr}\left(d_{i j r t}<0 \mid \iota_{t-1}\right)=\Phi\left(-f_{j}-f_{r}-\gamma \cdot r_{j r t-s}-\rho_{M} \cdot M_{t}-\sqrt{\rho} \cdot F \cdot \xi_{t-1}\right)
$$

This follows from the fact that knowledge of $\xi_{t-1}$ makes the term $F \cdot \xi_{t-1}$ fixed in $\xi_{t}=$ $F \cdot \xi_{t-1}+v_{t}$, but the innovation error $v_{t}$ still mixes into a standard normal variable with the idiosyncratic error $\varepsilon_{i j r t}$. It is then the case that $\operatorname{Pr}\left(d_{i j r t}<0 \mid \iota_{t-1}\right)=\operatorname{Pr}\left(\sqrt{\rho} v_{t}+\sqrt{1-\rho} \varepsilon_{i j r t}<\right.$ $\left.-f_{j}-f_{r}-\gamma \cdot r_{j r t-s}-\rho_{M} \cdot M_{t}-\sqrt{\rho} \cdot F \cdot \xi_{t-1}\right)$ and the expression in (5) follows. This same reasoning implies that the correlation of default events conditional on $\iota_{t-1} \equiv\left(f_{j}, f_{r}, r_{j r t-s}, M_{t}, \xi_{t-1}\right)$ is still $\rho .^{6}$

\footnotetext{
${ }^{6}$ The unconditional (on $\xi_{t}$ ) correlation across defaults of borrowers $i$ and $i^{\prime}$ is defined by $\operatorname{Corr}\left(d_{i j r t}, d_{i^{\prime} j r t}\right)=$ $1 /\left[1+(1-\rho)\left(1-F^{2}\right) / \rho\right]$. I focus on conditional correlation throughout the article, assuming that $\iota_{t-1}$ is the relevant information set for banks at $t$.
} 


\subsubsection{Two-Factor Default Risk Model}

I adapt the general specification of the model to allow for a common latent factor and a specific latent factor driving the defaults in the NFFs sectors $(r=1$ and $r=2)$. In the transition equation in $(3), \xi_{t}$ is a $(2 \times 1)$ vector and each component of $\xi_{t}$ follows an independent $\operatorname{AR}(1)$ process with a standard normal innovation shock. This specification implies that $\Sigma_{v}$ is restricted to a $(2 \times 2)$ identity matrix and $F$ is given by:

$$
F=\left[\begin{array}{cc}
F_{1} & 0 \\
0 & F_{2}
\end{array}\right]
$$

where $\left\{F_{1}, F_{2}\right\}$ denote the autoregressive coefficients for each risk factor. In the measurement equation, the term $\rho_{\varepsilon}$ is assumed positive, $\rho_{\varepsilon}>0$, and the vectors $\left\{\rho_{\xi, r}\right\}_{r=1}^{R}$ have positive loading on the common and specific latent factor. In a vertical stack of $\left\{\rho_{\xi, r}\right\}_{r=1}^{R}$, the restricted specification is:

$$
\left[\begin{array}{c}
\rho_{\xi, 1} \\
\rho_{\xi, 2} \\
\rho_{\xi, 3} \\
\rho_{\xi, 4}
\end{array}\right]=\left[\begin{array}{cc}
\rho_{\xi} & \rho_{\Delta \xi} \\
\rho_{\xi} & \rho_{\Delta \xi} \\
\rho_{\xi} & 0 \\
\rho_{\xi} & 0
\end{array}\right]
$$

where both $\rho_{\xi}$ and $\rho_{\Delta \xi}$ are real positive scalars. The random components of the model still combine into a normal random variable, but it is not generally standard. This fact does not alter the interpretation of the model, but it complicates the calculation of the correlation of two default events. If two loans of different borrowers $\left(i \neq i^{\prime}\right)$ belong to risk classes $r, r^{\prime} \in\{1,2\}$, the correlation of the default events of these two loans is:

$$
\operatorname{Corr}\left(d_{i j r t}, d_{i^{\prime} j r^{\prime} t} \mid \iota_{t-1}\right)=\frac{\rho_{\xi}^{2}+\rho_{\Delta \xi}^{2}}{\rho_{\xi}^{2}+\rho_{\Delta \xi}^{2}+\rho_{\varepsilon}^{2}}
$$


For $r, r^{\prime} \in\{3,4\}$, the analogous expression to equation (6) is $\operatorname{Corr}\left(d_{i j r t}, d_{i^{\prime} j r t} \mid \iota_{t-1}\right)=\rho_{\xi}^{2} /\left(\rho_{\xi}^{2}+\right.$ $\left.\rho_{\varepsilon}^{2}\right)$. If two loans belong to different borrowers $\left(i \neq i^{\prime}\right)$ and risk classes $\left(r \neq r^{\prime}\right)$ with $r \in\{1,2\}$ and $r^{\prime} \in\{3,4\}$, the correlation of default events of these two loans is:

$$
\operatorname{Corr}\left(d_{i j r t}, d_{i^{\prime} j r^{\prime} t} \mid \iota_{t-1}\right)=\frac{\rho_{\xi}^{2}}{\sqrt{\rho_{\xi}^{2}+\rho_{\Delta \xi}^{2}+\rho_{\varepsilon}^{2}} \sqrt{\rho_{\xi}^{2}+\rho_{\varepsilon}^{2}}}
$$

As the variable $\varepsilon_{i j r t}$ is still a standard normal, the expression in (1) for the conditional probability of default and the use of the inversion $\Phi(.)^{-1}$ in (2) are still valid.

\section{Data set}

\subsection{Default Rates}

I use data from the Credit Register of the Bank of Spain, CR henceforth, to calculate the default rate at the individual bank level for four different risk classes: loans to NFFs with notional amount above 1 million euros, loans to NFFs with notional amount below 1 million euros, mortgage loans to households and personal loans with no collateral. ${ }^{7}$ This database records quarterly information about all the loans granted by credit institutions in Spain with notional amounts above 6,000 EUR. The information on the CR regarding the default status of individual loans is used to form an average default rate for each risk class and each bank at the end of every quarter during the period January 2004-June $2010 .^{8}$

Table 1 and Figure 1 report information on the cross-sectional average of default rates for each risk class. The advent of the financial crisis in 2008 leads to an increase in the average default rates of all risk classes, and this evolution of the default rate series suggests the presence of common risk factors that affect all banks and risk classes. However, it is also important to notice that the differences in default rates across credit categories increase as the financial crisis persists in years 2009 and 2010. For example, the difference in the average default rate of mortgages and personal loans was approximately 85bp on the first quarter of 2004, whereas it claims to 336bp on the second quarter of 2010.

\footnotetext{
${ }^{7}$ Loans to non financial firms of all sizes include exposures to real estate development and construction firms.

${ }^{8}$ The determination of default status in the CR follows the Basel II definition for default events, i. e., obligations that are past due more than 90 days, or those that are considered to be highly unlikely to be repaid. For more information, see Basel Committee of Banking Supervision (2006), paragraphs 452-453, page 100.
} 
I report the cross-sectional coefficient of variation for every quarter and each separate risk class in Table 2 and Figure 2. This statistic reveals a decrease in the cross sectional dispersion in the crisis period starting in 2008. The coefficients of variation for the loans to NFFs above 1 million euros and the mortgage categories are quite stable, but the coefficients of variation for the loans to NFFs below 1 million euros and personal loans decrease respectively by $60 \%$ and 40\% from March 2004 to June 2010.

Figure 3 presents selected percentiles of the cross sectional distribution of default rates at different quarters and reveals a widening of this distribution. In particular, there is an increase in the difference between the average probability of default of the banks in the median and the $90^{\text {th }}$ percentile. This increase is particularly large for the loans to NFFs above 1 million euros, with a shift from a difference of $1.9 \%$ in March 2004 to $15.9 \%$ in June 2010, but it applies to all risk classes. The average cross sectional dispersion presented in Table 2 and Figure 2 decreases over time, but the extreme of the distribution diverges from its median in the period of financial crisis initiated in 2008. This evolution of the distribution of default rates highlights the potential importance of bank specific characteristics beyond common factors to explain the evolution of default rates.

\subsection{Loan Rates and Macroeconomic Variables}

The regulations of the Bank of Spain, in accordance with European Union Directives, require banks to report the average interest rate and volume of new loans and deposits to the Bank of Spain with a monthly frequency. ${ }^{9}$ I aggregate this information to a quarterly frequency and into four risk classes of loans: loans to NFFs with notional amounts above 1 million euros, loans to NFFs with notional amounts below 1 million euros, mortgage loans to households and

\footnotetext{
${ }^{9}$ The information requirements on interest rate reporting can be found in the Bank of Spain order 1/2010 published in BOE (2010), in accordance with the European Central Bank Regulations (CE) 290/2009. Banks with assets in excess of 1,500 million euros and euro denominated deposits in excess of 500 million euros are required to report interest rates. The Bank of Spain can also require interest rate information to banks that do not satisfy this threshold.
} 
other loans to households. ${ }^{10}$ The quarterly weighted average interest rates for each risk class and bank are calculated with the volume of new loans as weights.

I obtain the annual GDP growth at the end of each quarter from the Quarterly Spanish National Accounts elaborated by the National Institute of Statistics. The most common interbank reference rate for Spanish Banks is the Euribor 12 months, which is recovered from the Statistical Bulletin of the Bank of Spain. The sample period contains very different economic scenarios with high growth in the early years and stagnant and negative growth rates after 2008. There is also significant variation in the interbank reference rate during the sample period with a minimum of $1.2 \%$ and a maximum of $5.4 \%$. I report the summary statistics of the interest rate and macroeconomic variables in Table 3.

\section{Estimation}

\subsection{Maximum Likelihood Estimator}

I estimate the parameters $\Theta \equiv\left(f_{r}^{*}, f_{j}^{*}, \gamma^{*}, F, \beta_{M}, \beta_{\xi}, \Sigma_{\eta}, \Sigma_{v}\right)$ in the different specifications of the default risk model in Section 2 with the maximum likelihood method. ${ }^{11}$ The Kalman filter is used to control for the presence of common latent factors $\xi_{t}$ with possible autocorrelation. The Kalman filter recovers the latent factor series $\left\{\xi_{t}\right\}_{t=1}^{T}$ given an evaluation of parameters $\Theta$ with a series of linear forecasts $\left\{\widehat{\xi}_{t+1 \mid t}\right\}_{t=1}^{T}$ :

$$
\widehat{\xi}_{t+1 \mid t}=F \cdot \widehat{\xi}_{t \mid t-1}+F \cdot P_{t \mid t-1} \cdot \beta_{\xi}^{T}\left(\beta_{\xi} \cdot P_{t \mid t-1} \cdot \beta_{\xi}^{T}+\Sigma_{\eta}\right)^{-1} \widehat{\eta}_{t}
$$

where the superindex $T$ indicates the transpose of a matrix, $\widehat{\eta}_{t}=y_{t}-f^{*}-\gamma^{*} \cdot r_{t-s}-\beta_{M} \cdot M_{t}-$ $\beta_{\xi} \cdot \widehat{\xi}_{t \mid t-1}, \widehat{\xi}_{t+1 \mid t}$ is the best forecast of $\xi_{t+1}$ based on a linear function of $y_{t}, f^{*}, r_{t-s}, M_{t}$ and all

\footnotetext{
${ }^{10}$ The interest rate on other loans to households serves as a proxy for the rates on personal loans, as it weights the interest rates on consumer loans and other loans to households with no mortgage guarantees.

${ }^{11}$ The application of maximum likelihood estimation with Kalman filtering follows the presentation of Chapter 13 of Hamilton (1994).
} 
preceding lags of $y_{t}: y_{t-1}, y_{t-2}$, etc. The element $P_{t \mid t-1}$ is the mean squared error of the best linear forecast of $\widehat{\xi}_{t \mid t-1}$. For a generic date $t$, the mean squared error of forecast $\widehat{\xi}_{t+1 \mid t}$ is:

$$
P_{t+1 \mid t}=\left(F-K_{t} \cdot \beta_{\xi}\right) P_{t \mid t-1}\left(F^{T}-\beta_{\xi}^{T} \cdot K_{t}^{T}\right)+K_{t} \cdot \Sigma_{\eta} \cdot K_{t}^{T}+\Sigma_{v}
$$

where the term $K_{t}$ is defined by:

$$
K_{t}=F \cdot P_{t \mid t-1} \cdot \beta_{\xi}^{T}\left(\beta_{\xi} \cdot P_{t \mid t-1} \cdot \beta_{\xi}^{T}+\Sigma_{\eta}\right)^{-1}
$$

The procedure outlined in (8) and (9) requires starting values for $\widehat{\xi}_{1 \mid 0}$ and $P_{1 \mid 0}$ and I use the unconditional mean $E\left[\xi_{t}\right]$ and variance $E\left\{\left[\xi_{t}-E\left(\xi_{t}\right)\right]\left[\xi_{t}-E\left(\xi_{t}\right)\right]^{T}\right\}$ of $\xi_{t}$ to derive $\widehat{\xi}_{1 \mid 0}=0$ and $P_{1 \mid 0}=\Sigma_{\xi}$ with $\Sigma_{\xi}$ defined by $\Sigma_{\xi}=F \cdot \Sigma_{\xi} \cdot F^{T}+\Sigma_{v}$. The forecasts $\left\{\widehat{\xi}_{2 \mid 1}, P_{2 \mid 1}, \widehat{\xi}_{3 \mid 1}, P_{3 \mid 1}, \ldots\right\}$ are then obtained with recursive application of equations (8) and (9). Given the state-space representation in (3), the conditional density function of $y_{t}$ at a time $t$ is:

$$
\begin{aligned}
& \phi_{y_{t} \mid \Theta, r_{t-s}, M_{t}, y_{t-1}}\left(y_{t} \mid \Theta, r_{t-s}, M_{t}, y_{t-1}\right)= \\
& (2 \pi)^{-J \cdot 4}\left|\beta_{\xi} \cdot P_{t \mid t-1} \cdot \beta_{\xi}^{T}+\Sigma_{\eta}\right|^{-1 / 2} \\
& \times \exp \left\{-\frac{1}{2}\left(y_{t}-f^{*}-\gamma^{*} \cdot r_{t-s}-\beta_{M} \cdot M_{t}-\beta_{\xi} \cdot \widehat{\xi}_{t \mid t-1}\right)^{T} \times\left(\beta_{\xi} \cdot P_{t \mid t-1} \cdot \beta_{\xi}^{T}+\Sigma_{\eta}\right)^{-1}\right. \\
& \left.\times\left(y_{t}-f^{*}-\gamma^{*} \cdot r_{t-s}-\beta_{M} \cdot M_{t}-\beta_{\xi} \cdot \widehat{\xi}_{t \mid t-1}\right)\right\}
\end{aligned}
$$

The log likelihood function for a sample with a number of periods $T$ is then calculated as:

$$
\sum_{t=1}^{T} \log \phi_{y_{t} \mid \Theta, r_{t-s}, M_{t}, y_{t-1}}\left(y_{t} \mid \Theta, r_{t-s}, M_{t}, y_{t-1}\right)
$$

and the maximum likelihood estimator $\widehat{\Theta}$ maximizes the function in (10) subject to identification restrictions. It is not possible to identify separately the scale and signs of the latent factors and the factor loadings $\beta_{\xi}$. I then normalize the scale of $\Sigma_{v}$ to unity and restrict $\beta_{\xi}$ to have a negative sign. As indicated in Section 2, the factors $\xi$ are assumed to follow a covariance stationary process and the restrictions $F=0$ and $F \in(-1,1)$ are added to the specifications 
with i.i.d. and $\operatorname{AR}(1)$ dynamics. The estimates of the parameters $\widehat{\beta}_{\xi}$ can be used to measure the correlation between default events in the different models.

\section{Single Factor Default Risk Models}

In this base specification in line with Vasicek (2002), the estimated parameter $\widehat{\beta}_{\xi}$ on the common temporal effect provides an estimate of $\beta_{\xi}=-\sqrt{\rho} / \sqrt{1-\rho}$. It is then possible to recover an estimate of $\rho$ from $\beta_{\xi}^{2}=\rho / 1-\rho$. The estimated $\widehat{\rho}$ is:

$$
\widehat{\rho}=\widehat{\beta}_{\xi}^{2} /\left(1+\widehat{\beta}_{\xi}^{2}\right)
$$

The autocorrelation in the factor $\xi_{t}$ does not alter the fact that $\widehat{\beta}_{\xi}$ provides an estimate of $-\sqrt{\rho} / \sqrt{1-\rho}$ and we can still obtain $\widehat{\rho}$ with equation (11) for specifications with an $\operatorname{AR}(1)$ process for the common latent factor $\xi_{t}$.

\section{Two-Factor Default Risk Model}

The estimation of credit correlation is complicated by the presence of multiple factors, but it is possible to use equations (6) and (7) to recover the correlation of default events across households and NFFs. For the specification in subsection 2.2.3, a row of $\beta_{\xi}$ corresponding to risk class $r$ will be defined as $\beta_{\xi, r}=-\rho_{\xi, r} / \rho_{\varepsilon}=\left[-\rho_{\xi} / \rho_{\varepsilon} \quad-\rho_{\Delta \xi} / \rho_{\varepsilon}\right]$ for $r \in\{1,2\}$ and $\beta_{\xi, r}=\left[-\rho_{\xi} / \rho_{\varepsilon} \quad 0\right]$ for $r \in\{3,4\}$. The terms $\rho_{\xi}^{2} / \rho_{\varepsilon}^{2}$ and $\rho_{\Delta \xi}^{2} / \rho_{\varepsilon}^{2}$ are then identified from squaring each of the components of $\beta_{\xi, r}$. It is not necessary to identify separately $\rho_{\xi, r}$ and $\rho_{\varepsilon}$ to pin down the correlation across risk classes. For $r, r^{\prime} \in\{1,2\}$ and $i \neq i^{\prime}$, it is possible to divide numerator and denominator in (6) by $\rho_{\varepsilon}^{2}$ and obtain:

$$
\operatorname{Corr}\left(d_{i j r t}, d_{i^{\prime} j r^{\prime} t} \mid \iota_{t-1}\right)=\frac{\rho_{\xi}^{2} / \rho_{\varepsilon}^{2}+\rho_{\Delta \xi}^{2} / \rho_{\varepsilon}^{2}}{\rho_{\xi}^{2} / \rho_{\varepsilon}^{2}+\rho_{\Delta \xi}^{2} / \rho_{\varepsilon}^{2}+1}
$$

where all the terms can be estimated from $\widehat{\beta}_{\xi, r}$.

For $r, r^{\prime} \in\{3,4\}$, the division by $\rho_{\varepsilon}^{2}$ yields $\operatorname{Corr}\left(d_{i j r t}, d_{i^{\prime} j r t} \mid \iota_{t-1}\right)=\left(\rho_{\xi}^{2} / \rho_{\varepsilon}^{2}\right) /\left(\rho_{\xi}^{2} / \rho_{\varepsilon}^{2}+1\right)$, which for $\rho_{\varepsilon}^{2}=1-\rho=1-\rho_{\xi}^{2}$ would yield the same correlation as in the standard single factor 
model. If two loans belong to different borrowers and risk classes $\left(r \neq r^{\prime}\right)$ with $r \in\{1,2\}$ and $r^{\prime} \in\{3,4\}$, the normalization of $(7)$ by $\rho_{\varepsilon}^{2}$ still allows to estimate correlation:

$$
\begin{aligned}
\operatorname{Corr}\left(d_{i j r t}, d_{i^{\prime} j r^{\prime} t} \mid \iota_{t-1}\right) & =\frac{\rho_{\xi}^{2} / \rho_{\varepsilon}^{2}}{\left(1 / \rho_{\varepsilon}^{2}\right) \cdot \sqrt{\rho_{\xi}^{2}+\rho_{\Delta \xi}^{2}+\rho_{\varepsilon}^{2}} \sqrt{\rho_{\xi}^{2}+\rho_{\varepsilon}^{2}}} \\
& =\frac{\rho_{\xi}^{2} / \rho_{\varepsilon}^{2}}{\sqrt{\rho_{\xi}^{2} / \rho_{\varepsilon}^{2}+\rho_{\Delta \xi}^{2} / \rho_{\varepsilon}^{2}+1} \sqrt{\rho_{\xi}^{2} / \rho_{\varepsilon}^{2}+1}}
\end{aligned}
$$

\subsection{Inference}

The asymptotic results for the variance covariance matrix of the estimated $\widehat{\Theta}$ for a large time series are well known. In particular, the robust QML variance covariance estimate is defined by: $:^{12}$

$$
\widehat{\Sigma}_{Q M L}=\frac{1}{T} \cdot\left(\zeta_{H}(\widehat{\Theta}) \cdot \zeta_{O}(\widehat{\Theta})^{-1} \cdot \zeta_{H}(\widehat{\Theta})^{T}\right)^{-1}
$$

where the estimates of the Hessian $\zeta_{H}(\widehat{\Theta})$ and outer product estimate of $\zeta_{O}(\widehat{\Theta})$ of the log likelihood function with respect to parameters are given by:

$$
\begin{aligned}
\zeta_{H}(\widehat{\Theta}) & =-\frac{1}{T} \sum_{t=1}^{T} \frac{\partial^{2} \log \phi_{y_{t} \mid \Theta, r_{t-s}, M_{t}, y_{t-1}}(\widehat{\Theta}, .)}{\partial \Theta \partial \Theta^{T}} \\
\zeta_{O}(\widehat{\Theta}) & =\frac{1}{T} \sum_{t=1}^{T}\left[\frac{\partial \log \phi_{y_{t} \mid \Theta, r_{t-s}, M_{t}, y_{t-1}}(\widehat{\Theta}, .)}{\partial \Theta}\right] \cdot\left[\frac{\partial \log \phi_{y_{t} \mid \Theta, r_{t-s}, M_{t}, y_{t-1}}(\widehat{\Theta}, .)}{\partial \Theta}\right]^{T}
\end{aligned}
$$

The estimate $\widehat{\Sigma}_{Q M L}$ allows to infer the asymptotic variance of $\widehat{\rho}$ with a simple application of the delta method. For example, the one factor models imply that $\partial \widehat{\rho} / \partial \widehat{\beta}_{\xi}=2 \widehat{\beta}_{\xi} /\left(1+\widehat{\beta}_{\xi}\right)^{2}$ and the standard error is then $\sigma(\widehat{\rho})=2 \widehat{\beta}_{\xi} \cdot \sigma\left(\widehat{\beta}_{\xi}\right) /\left(1+\widehat{\beta}_{\xi}^{2}\right)^{2}$. An analogous calculation is completed for the calculation of the standard error of the correlation in the two-factor model.

The relatively short horizon of the sample calls for caution in using the asymptotic times series theory for the QML estimator. The analysis of dynamic factor models has been conducted mostly in a time series framework with a fixed cross section and a large time dimension. ${ }^{13}$

\footnotetext{
${ }^{12}$ See Watson (1989) and Hamilton (1994) for asymptotic results. I compute the derivatives in (14) with the numerical differentiation suite for Matlab ${ }^{\circledR}$ of John D'Errico, which is available at http://www.mathworks.com/matlabcentral.

${ }^{13}$ The classic references in the field include Geweke (1977), Sargent and Sims (1977) and Stock and Watson (1989). Hamilton (1994) provides a general exposition of this literature.
} 
However, there has been recent progress in the study of panel data sets with large cross sectional and time dimensions. Bai and Ng (2002), Stock and Watson (2002) and Forni et al. (2000) use principal components to estimate dynamic latent factor models with large panels. More closely related to the current article, Doz et al. (2012) show the consistency of the QML estimator of approximate factor models when both the cross section and time series dimension go to infinity. ${ }^{14}$ Gagliardini an Gourieroux (2010) study the efficient estimation of large dynamic non linear factor models. The concern over time series asymptotic results induce me to use nonparametric bootstrap to obtain robust confidence intervals. The basic steps of the bootstrap procedure are:

(1) Draw a random sample $b s$ of the model variables $\left\{y_{t, b s}, r_{t-s, b s}, M_{t, b s}\right\}_{t=1, \ldots, T}$ along the cross sectional dimension $j$. Each bank observation in the artificial sample, containing the data for all time periods and risk classes of bank $j$, is drawn with replacement from the original sample of bank data.

(2) Compute the maximum likelihood estimator $\widehat{\Theta}(b s)$ through maximization of the log likelihood function in (10) evaluated with the artificial sample data $\left\{y_{t, b s}, r_{t-s, b s}, M_{t, b s}\right\}_{t=1, \ldots, T}$.

(3) Repeat steps 1-2 a total number of $B S=250$ times. Calculate the confidence intervals for $\widehat{\Theta}$ from the $5^{\text {th }}$ and $95^{\text {th }}$ percentiles of the distribution of maximum likelihood estimates across artificial samples $\{\widehat{\Theta}(b s)\}_{b s=1, \ldots, B S}$.

The bootstrap confidence intervals with cross-sectional resampling could also apply in the case of a large scale latent factor model, with both large times series and cross sectional dimensions, as in Doz et al. (2012). Kapetanios (2008) establishes the superiority of cross-sectional resampling for a fixed-effect estimator in a class of common latent factor linear models. Temporal and block bootstrap sampling schemes could also be applied to obtain alternative estimates of confidence intervals.

\footnotetext{
${ }^{14}$ Approximate factor models allow for cross sectional correlation of idiosyncratic components whereas an exact factor model uses an i.i.d. assumption. Doz et al. (2012) use an exact factor model as proxy for an approximate factor model and show that the bias introduced by approximation disappears asymptotically. The results in Doz et al. (2012) apply to exact factor models as an special case.
} 


\section{Results}

\subsection{Estimates with Average Default Rate Data}

I estimate first the credit model with the average default rates for each class of risk (NFFs above 1 million euros, NFFs below 1 million euros, Mortgages and Personal Loans). The presentation of the model estimates in Table 4 with average default rates allows to set up the framework for presentation of results with a simple data set and provides a benchmark for the estimates with bank level data. The base specification in column (a) includes an i.i.d. common latent factor and fixed effects $f_{r}^{*}$ for each class of risk. The risk factors $\left\{f_{1}^{*}=-1.85, f_{2}^{*}=-1.70\right\}$ associated to loans with NFFs are greater than the risk factor $f_{4}^{*}=-2.29$ associated to mortgages. Note that the greater the estimate of $f_{r}^{*}$, the greater the probability of default in the formulas in (1) and (4). This result is natural, as entrepreneurs and managers in control of NFFs enjoy limited liability and have greater opportunities for risk-shifting than households with mortgage loans. It is harder to predict a priori the relative size of the fixed effect for personal loans. I find that $f_{3}^{*}=-1.97$ resulting in higher average probability of default than in the mortgage class, but still below the default rates in NFFs loans. The estimate of $\beta_{\xi}$ implies a relatively low correlation parameter $\rho=0.06$.

The specification in column (b) of Table 4 allows for $\mathrm{AR}(1)$ dynamics and the common latent factor is found to be highly autocorrelated, pointing to a limitation of the standard credit risk model in the Basel II framework. This result is in line with the persistence of credit risk factors in Jimenez and Mencía (2009) and the analysis in Kupiec (2009). The estimate of $\beta_{\xi}$ is much lower than in the base specification when persistence in the latent factor is recognized and correlation decreases to $\rho=0.003$. The specification in column (c) of Table 4 includes the second and third lags of GDP growth and the Euribor 12 months to control for the macroeconomic environment, producing less persistent estimates of the latent credit factor and low estimates of $\beta_{\xi}$ and correlation $\rho=0.001$. This result indicates that controlling for macroeconomic factors reduces the importance of the common latent factor. As expected, higher growth and lower interest rates are associated with lower default rates. The precision 
of the model estimates is high both according to the low QML standard errors and the narrow confidence intervals calculated with bootstrap sampling across the time dimension. ${ }^{15}$ However, the bootstrap confidence intervals do not allow to reject that the coefficients on the lags of the Euribor 12 months are equal to zero.

\subsection{Estimates with Bank Default Rate Data}

The Table 5 contains the model estimates with individual bank level data of the specifications used in Table 4 for aggregate data. The results on the fixed-effect of the risk class, macroeconomic factors and correlation are comparable in both tables, indicating that the use of aggregate data, which is easier to collect and analyze, would be sufficient to estimate the most basic specifications of the model in Section 2. However, the use of bank level data allows the inclusion as explanatory variables of bank fixed effects $f_{j}^{*}$ and the one year lag of the average interest rate $r_{j r t-4}(s=4)$ charged by each bank on the loans of each risk class. A lagged rather than a contemporaneous interest rate is used $(s=4)$ to recognize that newly granted loans do not default immediately, but that credit problems are revealed over time.

The correlation parameter is still $\rho \cong 0.06$ if an i.i.d. common latent factor is assumed, and it decreases significantly if persistence in the latent factor or macroeconomic variables are incorporated. As opposed to the estimation with aggregate data, the bootstrap confidence interval for the lags of the Euribor 12 month excludes zero and I can reject a nihil impact of the interbank rate. The coefficient on the interest rate lag $r_{j r t-4}$ is positive and significant according to QML standard errors. However, the bootstrap confidence interval on the coefficient on $r_{j r t-4}$ is wide and it does not exclude the zero value. Variable loan rates referenced to the Euribor 12 months are common in the Spanish credit sector and the model estimates seem to indicate that the interbank rate is more informative of the interest burden on borrowers than $r_{j r t-4}$, which is a proxy for the original interest rate on loan contracts. The bank level fixed effects improve the fit of the model to the data and recognize that the identity of the bank (organizational structure,

\footnotetext{
${ }^{15}$ The bootstrap procedure across the time dimension $t$ is analogous to the cross-sectional bootstrap described in Section 4. In step (1), I draw time periods with replacement from the original sample, with each draw containing the information of all risk classes at period $t$.
} 
risk management practices, etc.) has a differential impact on the probability of default of a loan.

In Table 6, I present a selection of the model estimates with the two-factor model. The columns (a) and (b) of Table 6 report the results for specifications with two latent factors with i.i.d. and $\mathrm{AR}(1)$ dynamics and fixed-effects for the risk class. As in Tables 4 and 5, the impact of the latent factor declines significantly with the AR(1) specification. The inclusion of the second latent factor allows to estimate separate correlations for loans to NFFs and households, 0.055 and 0.049 respectively for the specification (a), but the results are not significantly different with respect to the findings in the simpler single factor specification in Table 5 . The specification (c) includes the full set of macroeconomic and interest rate controls together with bank level fixed effects and two i.d.d. latent factors. The explicit inclusion of the macroeconomic factors drains again explanatory power from the credit latent factor model and the estimated correlation is low, 0.007 and 0.002 and for NFFs and households. The correlation for NFFs in the model with macroeconomic factors is higher than in the single factor specification, but it is still very low.

\subsection{Model Implications for Regulatory Policy}

The estimates for the standard credit risk model of Vasicek (2002) correspond with the results for specification (a) in Table 5. For this model, the parameter $\rho$ lies in the range $[0.05,0.07]$ and points to reduced correlation across loan defaults. The inclusion of the $\operatorname{AR}(1)$ dynamics in the common latent factor and macroeconomic variables further reduces the estimated correlation. In the framework of Martinez-Miera and Repullo (2010), low correlation implies a generally positive relation between the number of competing banks and the probability of bank failure. ${ }^{16}$ The empirical results in this article indicate then that the theoretical results of Boyd and De Nicolo (2005) would be of limited interest for the Spanish credit institutions during the period of study. Given the low correlation, it would be expected that the reduction of the number

\footnotetext{
${ }^{16}$ The number of banks that minimizes the probability of bank failure with $\rho<0.1$ is 1 for most of the risk-shifting possibilities in the calibration considered in Martinez-Miera and Repullo(2010). See Figure 3 and Figure 6 in Martinez-Miera and Repullo (2010) for results with Cournot and circular city models.
} 
of competing banks through merger processes would both soften competition and reduce the probability of bank failure.

The estimates of the credit model only provide an indication of how to apply the formal models of Martinez-Miera and Repullo (2010) and Boyd and De Nicolo (2005). The conclusions of the combination of the credit model estimates and these theories must be examined with care. For example, these models consider that banks choose the level of loanable funds they provide in a single good Cournot framework, whereas the credit model considers four risk classes and this opens the question of what would be the effect of low correlation in a formal model in which banks choose the amount of credit provided to different sectors. Despite this caveat, the estimated model provides a more informed estimate of correlation for the Spanish financial system than simple calibrations or estimates based on aggregate market data for listed institutions. This estimation contributes then to make a better judgement of the effects of competition on the stability of the banking system.

\subsection{Stress Tests for Individual Bank Loan Portfolios}

I use the model to calculate the deterioration of default rates that results from an adverse macroeconomic shock. The inclusion of the bank level loan rates in the model also allows to check the sensitivity of individual bank default rates to the loan rate policies of different banks. More specifically, I use the formula (1) to calculate the probability of default for each bank and risk class for both a central scenario and multiple adverse scenarios. In the central scenario, GDP growth and the Euribor 12 months are fixed at the mean values of $1.8 \%$ and $3.0 \%$ for the period 2004-2010 and the latent factor is assumed equal to the unconditional mean value $\xi_{t}=0$. For the adverse scenarios, I consider a latent factor value of $\xi_{t}=-2.3$ that corresponds with the $1 \%$ percentile of the unconditional distribution of this variable. The model estimates indicate that high interbank rates and low GDP growth in the quarters preceding a given date are associated with higher default rates. I use then in the adverse scenarios progressively higher negative deviations of GDP growth, with a limit deviation of $-4 \%$, and positive deviations of 
the Euribor 12 months, with a limit deviation of $+2 \%$. The bank level loan rates are fixed at the period average for each bank and risk class.

I report the change in the average probability of default of each risk class in Figure 4. Confidentiality requirements do not allow to report the results at the bank level, but individual estimates can be used for regulatory purposes. The pattern of responses of the probability of default to the macroeconomic shocks is comparable across risk classes, with a mildly convex relation between default rates and the shocks to GDP growth and the Euribor 12 months. For example, the default rate for loans to NFFs above 1 million euros increases by 0.025 in the $[0,1]$ scale when GDP growth and the Euribor 12 months deviate by $-2 \%$ and $1 \%$ from their period averages. Additional shocks of $-2 \%$ and $1 \%$ to each of these macroeconomic variables bring an increase in default rates of $0.0589-0.025=0.034$. The levels of default rates in the panels of Figure 4 are different across risk classes, with the lowest increase in default rates corresponding to mortgages. The maximum variation of 0.04 in mortgage loans can however generate substantial credit losses, as the exposure to this form of credit is large for Spanish credit institutions. ${ }^{17}$

The Figure 5 reports the change in average default rates as response to a level increase in all bank level loan rates above their period average values. This calculation is performed both at the central scenario and at the most adverse scenario with GDP growth a $4 \%$ below average and the Euribor 12 months 2\% above average. This calculation could also be performed at the individual bank level. In the range of loan rates used for the stress exercise, the relation between probability of default and individual loan rates is approximately linear and increasing, and the pattern of responses to macroeconomic shocks is again similar across risk classes. The range of deviations above the period average for loan rates is relatively ample, with a maximum deviation of $+4 \%$, but the implied maximum changes in default rates are moderate. For example, the default rate of loans to NFFs below 1 million euros would increase by 0.003 with an increase of $4 \%$ of bank loan rates in the central scenario and above 0.008 in the adverse scenario. This low impact of loan rates on probability of default with respect to the macroeconomic variables

\footnotetext{
${ }^{17}$ The Statistical Bulletin of the Bank of Spain reports in Section 4.14 an aggregate figure of 612,000 million euros for the total household mortgages of credit institutions at year end 2010.
} 
follows from the low estimates of the coefficient on $r_{t-s}$ relative to the coefficients on the Euribor 12 months and GDP growth. To interpret these results, it must also be taken into account that banks do not necessarily increase loan rates when macroeconomic forecasts are negative. Figure 5 provides sensitivity analysis rather than the impact on default rates of the expected changes of loan rates in stressed macroeconomic scenarios.

\section{Conclusion}

This article has estimated the standard credit risk model of the Basel II framework with a maximum likelihood methodology that controls for the latent common factor with the Kalman filter. This approach allows to bring the standard credit model directly to credit data rather than relying on market data for listed banks and corporations. This framework also allows to estimate generalizations of the standard credit model with macroeconomic factors, autocorrelation in the latent credit risk factor and multiple factors with different effects on different loan classes. The recognition of the persistence of the latent factor or the inclusion of lags of GDP growth and interbank rates reduce the estimated correlation across loans with respect to the standard credit risk model. For both regulators and banks, these results point to the importance of evaluating the robustness to modelling assumptions of credit performance forecasts.

The model can be used to compute the probability of default of loans to non financial firms, mortgages and personal loans under adverse macroeconomic scenarios and stressed values of latent credit factors. I find a significant increase of default rates across all risk categories as GDP growth and interbank rates deviate from their average values. An individual bank that sets loan rates above average levels can expect moderate further deterioration of its credit performance beyond the impact of macroeconomic shocks.

A key insight from the recent theoretical literature studying the relation between banking competition and the probability of bank failure is that this relation is a function of credit risk and, in particular, the correlation of defaults across loans. The empirical results in the article point to relatively low correlation and suggest, in the light of the theoretical literature, that 
consolidation in the Spanish banking sector can improve financial stability. Additionally, the empirical finding of persistence of credit factors and the differences of credit performance across sectors suggests that it would be of interest to examine the relation between financial stability and banking competition in these more general credit risk frameworks. 


\section{References}

[1] Acharya, V., 2009, A Theory of Systemic Risk and Design of Prudential Bank Regulation, Journal of Financial Stability, Vol. 5, pp. 224-225

[2] Bai, J., and S. Ng, 2002, Determining the Number of Factors in Approximate Factor Models, Econometrica 70, pp. 191-221

[3] Basel Comittee on Banking Supervision, 2004, International Convergence of Capital Measurement and Capital Standards. A Revised Framework. Bank of International Settlements.

[4] Basel Comittee on Banking Supervision, 2006, Basel II: International Convergence of Capital Measurement and Capital Standards: A Revised Framework - Comprehensive Version. Bank of International Settlements.

[5] Boletín Oficial del Estado (2010). Circular 1/2010 del Banco de España sobre estadísticas de los tipos de interés que se aplican a los depósitos y a los créditos frente a los hogares y las sociedades no financieras, $\mathrm{N}^{o} 31$, pp. 10555-10565

[6] Boyd, J., and G. De Nicolo, 2005, The Theory of Bank Risk-Taking and Competition Revisited, Journal of Finance, Vol. 60, pp 1329-1343

[7] Chiappori, P. A., D. Perez-Castrillo, and T. Verdier, 1995, Spatial Competition in the Banking System: Localization, Cross Subsidies, and the Regulation of Deposit Rates, European Economic Review, Vol. 39, pp. 889-918

[8] Doz, C., Giannone, D., and L. Reichlin, 2012, A Quasi Maximum Likelihood Approach for Large Approximate Dynamic Factor Models, Review of Economics and Statistics, Posted Online

[9] Duffie, D., Eckner, A., Horel, G., L. Saita, 2009, Frailty Correlated Default, Journal of Finance, Vol. 64, pp. 2089-2123

[10] Forni, M., M. Hallin, M. Lippi, and L. Reichlin, 2000, The Generalized Dynamic Factor Model: Identification and Estimation, Review of Economics and Statistics, pp. 540-554

[11] Gagliardini, P., and C. Gourieroux, 2010, Efficiency in Large Dynamic Panel Models with Common Factor, CREST Working Paper 2010-05

[12] Geweke, J. F., 1977, The dynamic factor analysis of economic time series models. In D. Aigner and A. Goldberger, editors, Latent Variables in Socioeconomic Models, NorthHolland, pp. 365-383

[13] Gordy, M., 2003, A Risk-Factor Model Foundation for Ratings-Based Bank Capital Rules, Journal of Financial Intermediation, 12, pp. 199-232

[14] Hamilton, J. D., 1994, Time Series Analysis, Princeton University Press, Princeton, NJ

[15] Hellmann, T. F., K. C. Murdock, and J. E. Stiglitz, 2000, Liberalization, Moral Hazard in Banking, and Prudential Regulation: Are Capital Requirements Enough? American Economic Review, Vol. 90, pp. 147-65 
[16] Jimenez, G., and J. Mencía, 2009, Modelling the Distribution of Credit Losses with Observable and Latent Factors, Journal of Empiriral Finance, Vol. 16, pp. 235-253

[17] Jimenez, G., and J. Saurina, 2006, Credit Cycles, Credit Risk and Prudential Regulation, International Journal of Central Banking, Vol. 2, pp. 65-98

[18] Jiménez, G., Lopez, J. A., and J. Saurina, 2009, Empirical Analysis of Corporate Credit Lines, Review of Financial Studies, Vol. 22, pp. 5069-5098

[19] Jimenez, G., Salas, V., and J. Saurina, 2006, Determinants of Collateral, Journal of Financial Economics, Vol. 81, pp. 255-281

[20] Kapetanios, G., 2008, A Bootstrap Procedure for Panel Data Sets with Many Crosssectional Units, Econometrics Journal, Vol. 11, pp. 377-395

[21] Kupiec, P., 2009, How well does the Vasicek-Basel AIRB Model Fit the Data? Evidence from a Long Time Series of Corporate Credit Rating Data, FDIC Working Paper 2009-10

[22] López, J., 2004, The Empirical Relation between Average Asset Correlation, Firm Probability of Default, and Asset Size, Journal of Financial Intermediation, Vol. 13, pp. 265-283

[23] Martinez-Miera, D., and R. Repullo, 2010, Does Competition Reduce the Risk of Bank Failure?, Review of Financial Studies, Vol. 23, pp. 3638-3664

[24] Matutes, C., and X. Vives, 2000, Imperfect Competition, Risk, and Regulation in Banking, European Economic Review, Vol. 44, pp. 1-34

[25] Repullo, R., 2004, Capital Requirements, Market Power, and Risk-Taking in Banking, Journal of Financial Intermediation, Vol. 13, pp. 156-182.

[26] Rodriguez A. and C. Trucharte, 2007, Loss coverage and Stress Testing Mortgage Portfolios: A Non-Parametric Approach, Journal of Financial Stability, Vol. 3, pp. 342-367

[27] Sargent, T. J., and C. Sims, 1977, Business Cycle Modelling without Pretending to have too much a priori Economic Theory. In Christopher Sims, editor, New Methods in Business Cycle Research. Federal Reserve Bank of Minneapolis.

[28] Stiglitz, J. E., and A. Weiss, 1981, Credit Rationing in Markets with Imperfect Information, The American Economic Review, Vol. 71, pp. 393-410

[29] Stock, J. H., and M. W. Watson, 1989, New indexes of coincident and leading economic indicators. In Olivier J. Blanchard and Stanley Fischer, editors, NBER Macroeconomics Annual, MIT Press, pp. 351-393

[30] Stock, J. H., and M. W. Watson, 2002, Forecasting Using Principal Components from a Large Number of Predictors, Journal of the American Statistical Association, Vol. 97, pp. $147-162$

[31] Vasicek, O., 2002, Loan Portfolio Value, Risk, Vol. 15, pp. 160-162

[32] Watson, M. W., 1989, Recursive Solution Methods for Dynamic Linear Rational Expectations Models, Journal of Econometrics, Vol. 41, pp. 65-89 
Table 1 - Probability of default (Average, Cross-sectional Distribution)

\begin{tabular}{|c|c|c|c|c|}
\hline Date & $\begin{array}{c}\text { Non Financial } \\
\text { Firms Above 1M }\end{array}$ & $\begin{array}{c}\text { Non Financial } \\
\text { Firms Below 1M }\end{array}$ & Personal & Mortgages \\
\hline 200406 & $2.00 \%$ & $3.27 \%$ & $1.40 \%$ & $0.54 \%$ \\
\hline 200412 & $1.76 \%$ & $2.97 \%$ & $1.31 \%$ & $0.50 \%$ \\
\hline 200506 & $1.91 \%$ & $2.99 \%$ & $1.74 \%$ & $0.78 \%$ \\
\hline 200512 & $1.87 \%$ & $2.80 \%$ & $1.67 \%$ & $0.66 \%$ \\
\hline 200606 & $1.87 \%$ & $2.76 \%$ & $1.62 \%$ & $0.65 \%$ \\
\hline 200612 & $1.83 \%$ & $2.79 \%$ & $1.69 \%$ & $0.63 \%$ \\
\hline 200706 & $2.00 \%$ & $2.85 \%$ & $1.89 \%$ & $0.75 \%$ \\
\hline 200712 & $2.19 \%$ & $3.25 \%$ & $2.03 \%$ & $0.90 \%$ \\
\hline 200806 & $3.03 \%$ & $4.18 \%$ & $2.58 \%$ & $1.33 \%$ \\
\hline 200812 & $5.78 \%$ & $6.79 \%$ & $3.63 \%$ & $2.08 \%$ \\
\hline 200906 & $9.16 \%$ & $10.17 \%$ & $5.09 \%$ & $2.76 \%$ \\
\hline 200912 & $9.69 \%$ & $11.32 \%$ & $5.44 \%$ & $2.40 \%$ \\
\hline 201006 & $10.00 \%$ & $12.49 \%$ & $5.84 \%$ & $2.48 \%$ \\
\hline
\end{tabular}

Note. This table reports at the end of each quarter in the sample period the cross-sectional average of the probability of default for each of the risk classes of loan contracts: loans to non financial firms above 1 million euros, loans to non financial firms below 1 million euros, mortgages and personal loans. Loans to non financial firms of all sizes include exposures to real estate development and construction firms. 
Table 2 - Probability of Default (Coefficient of Variation, Cross-sectional Distribution)

\begin{tabular}{|c|c|c|c|c|}
\hline Date & \multicolumn{1}{c}{$\begin{array}{c}\text { Non Financial } \\
\text { Firms Above 1M }\end{array}$} & $\begin{array}{c}\text { Non Financial } \\
\text { Firms Below 1M }\end{array}$ & \multicolumn{1}{l}{ Personal } & Mortgages \\
\hline 200406 & 0.90 & 0.77 & 0.80 & 0.70 \\
200412 & 1.01 & 0.83 & 0.73 & 0.65 \\
200506 & 1.02 & 0.75 & 0.62 & 0.61 \\
200512 & 1.02 & 0.76 & 0.65 & 0.62 \\
200606 & 0.97 & 0.71 & 0.58 & 0.63 \\
200612 & 0.99 & 0.69 & 0.57 & 0.65 \\
200706 & 1.00 & 0.65 & 0.58 & 0.70 \\
200712 & 1.03 & 0.71 & 0.54 & 0.82 \\
200806 & 0.85 & 0.61 & 0.54 & 0.87 \\
200812 & 0.83 & 0.52 & 0.53 & 0.88 \\
200906 & 0.76 & 0.44 & 0.51 & 0.74 \\
200912 & 0.79 & 0.47 & 0.54 & 0.62 \\
201006 & 0.84 & 0.45 & 0.53 & 0.60 \\
\hline
\end{tabular}

Note. This table reports at the end of each quarter in the sample period the crosssectional coefficient of variation of the probability of default for each of the risk classes of loan contracts: loans to non financial firms above 1 million euros, loans to non financial firms below 1 million euros, mortgages and personal loans. Loans to non financial firms of all sizes include exposures to real estate development and construction firms. 
Table 3 - Summary Statistics (Interest Rate and Macro Variables)

\begin{tabular}{|c|c|c|c|c|}
\hline & Mean & Std. Deviation & Min & Max \\
\hline $\begin{array}{l}\text { Loan rates for Non Financial Firms } \\
\text { above } 1 \text { million euros }\end{array}$ & 4.0 & 1.2 & 1.1 & 8.0 \\
\hline $\begin{array}{l}\text { Loan rates for Non Financial Firms } \\
\text { below } 1 \text { million euros }\end{array}$ & 4.6 & 1.1 & 1.8 & 7.5 \\
\hline Loan rates for Personal Loans & 8.1 & 2.9 & 1.1 & 21.2 \\
\hline Loan rates for Mortgages & 4.1 & 1.0 & 1.7 & 6.7 \\
\hline Euribor 12 Months & 3.0 & 1.3 & 1.2 & 5.4 \\
\hline GDP Annual Growth Rate & 1.8 & 2.8 & -4.5 & 4.3 \\
\hline
\end{tabular}


Table 4 - Single Factor Risk Model with Aggregate Data

\begin{tabular}{|c|c|c|c|c|c|c|c|c|c|c|c|c|}
\hline \multirow[b]{3}{*}{$F$} & \multicolumn{4}{|l|}{ (a) } & \multicolumn{4}{|l|}{ (b) } & \multicolumn{4}{|l|}{ (c) } \\
\hline & \multicolumn{2}{|c|}{ Coefficient Sd Error } & \multicolumn{2}{|c|}{ p5(BS) p95(BS) } & \multicolumn{2}{|c|}{ Coefficient S d Error } & \multicolumn{2}{|c|}{ p5(BS) p95(BS) } & \multicolumn{2}{|c|}{ Coefficient Sd Error } & \multicolumn{2}{|c|}{ p5(BS) p95(BS } \\
\hline & . & & & & 0.9844 & $0.0067^{* * *}$ & 0.9643 & 0.9858 & 0.5093 & 0.2104 & 0.2933 & 0.9442 \\
\hline$f$ & & & & & & & & & & & & \\
\hline NFFs (> 1m eur) & -1.8468 & $0.0619^{* * *}$ & -1.9364 & -1.7540 & -1.7370 & $0.2750^{* * *}$ & -1.7965 & -1.7060 & -1.9544 & $0.0433^{* * *}$ & -2.0253 & -1.8721 \\
\hline NFFs $(<1 \mathrm{~m}$ eur $)$ & -1.6964 & $0.0543^{* * *}$ & -1.7778 & -1.6155 & -1.5865 & $0.2705^{* * *}$ & -1.6349 & -1.5664 & -1.8040 & $0.0439^{* * *}$ & -1.8752 & -1.7184 \\
\hline Personal & -1.9717 & $0.0433^{* * * *}$ & -2.0407 & -1.9046 & -1.8619 & $0.2730^{* * * *}$ & -1.8964 & -1.8584 & -2.0793 & 0.0490 **** & -2.1602 & -1.9853 \\
\hline Mortgages & -2.2999 & $0.0452^{* * *}$ & -2.3761 & -2.2339 & -2.1901 & $0.2756^{* * *}$ & -2.2315 & -2.1780 & -2.4075 & $0.0486^{* * *}$ & -2.4866 & -2.3121 \\
\hline$\Delta G D P \%(t-2)$ & & & & & & & & & -0.0429 & $0.0161^{* * * *}$ & -0.0834 & -0.0086 \\
\hline$\Delta \mathrm{GDP} \%(\mathrm{t}-3)$ & & & & & & & & & -0.0565 & $0.0175^{* * *}$ & -0.0916 & -0.0202 \\
\hline Euribor (t-2) & & & & & & & & & 0.0466 & $0.0213^{* *}$ & -0.0005 & 0.1146 \\
\hline Euribor (t-3) & & & & & & & & & 0.0566 & $0.0258^{* *}$ & -0.0215 & 0.1088 \\
\hline$\beta \xi$ & -0.2567 & $0.0253^{* * *}$ & -0.2852 & -0.2060 & -0.0554 & $0.0088^{* * *}$ & -0.0810 & -0.0524 & -0.0318 & $0.0066^{* * *}$ & -0.0344 & -0.0146 \\
\hline$\Sigma \eta$ & 0.0037 & $0.0007^{* * *}$ & 0.0025 & 0.0045 & 0.0034 & $0.0006^{* * *}$ & 0.0022 & 0.0043 & 0.0036 & $0.0007^{* * *}$ & 0.0023 & 0.0044 \\
\hline $\log l k$ & 88.4 & & & & 124.6 & & & & 134.7 & & & \\
\hline$\rho$ & 0.0618 & $0.0114^{* * * *}$ & 0.0407 & 0.0752 & 0.0031 & $0.0010^{* * * *}$ & 0.0027 & 0.0065 & 0.0010 & $0.0004^{* *}$ & 0.0002 & 0.0012 \\
\hline Observations & 104 & & & & 104 & & & & 104 & & & \\
\hline Periods & 26 & & & & 26 & & & & 26 & & & \\
\hline
\end{tabular}

Note. (i) The specification (a) uses fixed effects $f$ for each risk class and an i.i.d. common latent factor $(F=0)$, specification (b) adds $\operatorname{AR}(1)$ dynamics to the common latent factor $(-1<F<1)$ and specification (c) adds two and three quarter lags of annual GDP growth $(\triangle G D P \%)$ and the interbank rate (Euribor) as exogenous explanatory variables to the specification (b). The standard errors are calculated with the asymptotic QML formula in equation (14) and confidence intervals, p5(BS) and p95(BS), are derived with bootstrap sampling across the time dimension.

(ii) Significant coefficients with QML standard errors at the $10 \%(5 \%, 1 \%)$ are marked with $\left.{ }^{* * *},{ }^{* *}\right)$. 
Table 5 - Single Factor Risk Model with Bank Level Data

\begin{tabular}{|c|c|c|c|c|c|c|c|c|c|c|c|c|}
\hline \multirow[b]{3}{*}{$F$} & \multicolumn{4}{|l|}{ (a) } & \multicolumn{4}{|l|}{ (b) } & \multicolumn{4}{|l|}{ (c) } \\
\hline & Coefficient & d Error & $\mathrm{p5}$ (BS) & p95(BS) & Coefficient & d Error & $\mathrm{p5}(\mathrm{BS})$ & p95(BS) & Coefficient & Sd Error & p5(BS) & p95(BS) \\
\hline & . & . & . & & 0.9846 & $0.0072^{* * * *}$ & 0.9812 & 0.9862 & 0.6158 & $0.1761^{* * *}$ & 0.5184 & 0.6852 \\
\hline \multicolumn{13}{|l|}{$f$} \\
\hline NFFs (> 1m eur) & -2.1237 & $0.0541^{* * * *}$ & -2.2166 & -2.0339 & -2.0061 & $0.2798^{* * *}$ & -2.0972 & -1.9138 & -2.2737 & $0.0408^{* * * *}$ & -2.3844 & -2.1532 \\
\hline NFFs $(<1 \mathrm{~m}$ eur $)$ & -1.7838 & $0.0502^{* * * *}$ & -1.8242 & -1.7419 & -1.6662 & $0.2767^{* * *}$ & -1.7085 & -1.6233 & -1.9385 & $0.0429^{* * * *}$ & -2.0183 & -1.8603 \\
\hline Personal & -2.0510 & $0.0371^{* * * *}$ & -2.0933 & -2.0098 & -1.9334 & $0.2792^{* * * *}$ & -1.9776 & -1.8908 & -2.2346 & $0.0479^{* * * * *}$ & -2.3915 & -2.0832 \\
\hline Mortgages & -2.4154 & $0.0378^{* * * *}$ & -2.4740 & -2.3600 & -2.2978 & $0.2816^{* * * *}$ & -2.3503 & -2.2478 & -2.5666 & $0.0466^{* * * *}$ & -2.6494 & -2.4790 \\
\hline$\Delta \mathrm{GDP} \%(\mathrm{t}-2)$ & & & & & & & & & -0.0484 & $0.0144^{* * * *}$ & -0.0566 & -0.0398 \\
\hline$\Delta \mathrm{GDP} \%(\mathrm{t}-3)$ & & & & & & & & & -0.0439 & $0.0149^{* * * *}$ & -0.0492 & -0.0369 \\
\hline Euribor (t-2) & & & & & & & & & 0.0460 & $0.0183^{* *}$ & 0.0352 & 0.0579 \\
\hline Euribor (t-3) & & & & & & & & & 0.0604 & $0.0214^{* * * *}$ & 0.0485 & 0.0726 \\
\hline$r_{j r t-4}$ & & & & & & & & & 0.0088 & $0.0021^{* * * *}$ & -0.0184 & 0.0351 \\
\hline Bank Fixed Effects & Yes & & & & Yes & & & & Yes & & & \\
\hline $\boldsymbol{\beta}_{\xi}$ & -0.2498 & $0.0284^{* * * *}$ & -0.2801 & -0.2342 & -0.0562 & $0.0092^{* * * *}$ & -0.0628 & -0.0542 & -0.0308 & $0.0054^{* * * *}$ & -0.0386 & -0.0281 \\
\hline$\Sigma_{\eta}$ & 0.1014 & $0.0045^{* * * *}$ & 0.0881 & 0.1255 & 0.1013 & $0.0045^{* * *}$ & 0.0893 & 0.1257 & 0.1012 & $0.0045^{* * * *}$ & 0.0897 & 0.1226 \\
\hline $\log 1 k$ & $\begin{array}{l}-1488.6 \\
\end{array}$ & & & & -1454.2 & & & & -1438.8 & & & \\
\hline$\rho$ & 0.0587 & $0.0126^{* * * *}$ & 0.0520 & 0.0728 & 0.0031 & $0.0010^{* * * *}$ & & & 0.0009 & $0.0003^{* * * *}$ & 0.0008 & 0.0015 \\
\hline Observations & 5408 & & & & 5408 & & & & 5408 & & & \\
\hline Banks & 52 & & & & 52 & & & & 52 & & & \\
\hline Periods & 26 & & & & 26 & & & & 26 & & & \\
\hline
\end{tabular}

Note. (i) The specification (a) uses fixed effects $f$ for each risk class and individual bank, and an i.i.d. common latent factor $(F=0)$, specification (b) adds $\operatorname{AR}(1)$ dynamics to the common latent factor $(-1<F<1)$ and specification (c) adds two and three quarter lags of annual GDP growth $(\triangle G D P \%)$ and the interbank rate (Euribor) together with the one year lag of the interest rate of bank $j$ on loans of class $r\left(r_{j r t-4}\right)$ as exogenous explanatory variables to the specification (b). The standard errors are calculated with the asymptotic QML formula in equation (14) and confidence intervals, p5(BS) and p95(BS), are derived with bootstrap sampling across the cross sectional dimension $j$.

(ii) Significant coefficients with QML standard errors at the $10 \%(5 \%, 1 \%)$ are marked with ${ }^{*}(* * * *)$. 
Table 6 - Two-Factor Risk Model with Bank Level Data

\begin{tabular}{|c|c|c|c|c|c|c|c|c|c|c|c|c|}
\hline \multirow[b]{3}{*}{$F$} & \multicolumn{4}{|l|}{ (a) } & \multicolumn{4}{|l|}{ (b) } & \multicolumn{4}{|l|}{ (c) } \\
\hline & Coefficient & Sd Error & p5(BS) & p95(BS) & Coefficient & d Error & p5(BS) & p95(BS) & Coefficient & Sd Error & p5(BS) & p95(BS) \\
\hline & . & . & & & 0.9844 & $0.0068^{* * *}$ & 0.9810 & 0.9862 & . & . & & \\
\hline & . & & & & 0.9249 & $0.0286^{* * * *}$ & 0.9100 & 0.9394 & . & . & & \\
\hline \multicolumn{13}{|l|}{$f$} \\
\hline NFFs (> 1m eur) & -2.1170 & $0.0596^{* * *}$ & -2.2571 & -1.9873 & -1.9914 & $0.2726^{* * *}$ & -2.1019 & -1.8512 & -2.2858 & $0.0336^{* * *}$ & -2.3991 & -2.1554 \\
\hline NFFs $(<1 \mathrm{~m}$ eur $)$ & -1.7771 & $0.0545^{* * *}$ & -1.8358 & -1.7202 & -1.6514 & $0.2690^{* * *}$ & -1.7007 & -1.5900 & -1.9508 & $0.0347^{* * *}$ & -2.0434 & -1.8606 \\
\hline Personal & -2.0443 & $0.0435^{* * * *}$ & -2.0846 & -1.9997 & -1.9726 & $0.2681^{* * *}$ & -2.0124 & -1.9133 & -2.2478 & $0.0393^{* * *}$ & -2.4061 & -2.0812 \\
\hline Mortgages & -2.4087 & $0.0449^{* * *}$ & -2.4799 & -2.3516 & -2.3371 & $0.2706^{* * *}$ & -2.4006 & -2.2722 & -2.5788 & $0.0391^{* * *}$ & -2.6730 & -2.4821 \\
\hline$\Delta \mathrm{GDP} \%(\mathrm{t}-2)$ & & & & & & & & & -0.0485 & $0.0223^{* *}$ & -0.0559 & -0.0405 \\
\hline$\Delta \mathrm{GDP} \%(\mathrm{t}-3)$ & & & & & & & & & -0.0347 & 0.0227 & -0.0411 & -0.0276 \\
\hline Euribor (t-2) & & & & & & & & & 0.0600 & $0.0253^{* *}$ & 0.0484 & 0.0719 \\
\hline Euribor (t-3) & & & & & & & & & 0.0431 & 0.0326 & 0.0314 & 0.0556 \\
\hline$r_{j r t-4}$ & & & & & & & & & 0.0091 & $0.0018^{* * * *}$ & -0.0202 & 0.0376 \\
\hline Bank Fixed Effects & No & & & & No & & & & Yes & & & \\
\hline \multirow[t]{3}{*}{$\beta_{\xi}$} & -0.2278 & $0.0232^{* * *}$ & -0.2462 & -0.2076 & -0.0514 & $0.0080^{* * *}$ & -0.0558 & -0.0482 & -0.0398 & $0.0056^{* * * *}$ & -0.0585 & -0.0293 \\
\hline & -0.0756 & $0.0117^{* * *}$ & -0.0986 & -0.0527 & -0.0357 & $0.0037^{* * *}$ & -0.0422 & -0.0304 & -0.0730 & $0.0116^{* * * *}$ & -0.1009 & -0.0576 \\
\hline & 0.1619 & $0.0050^{* * *}$ & 0.1156 & 0.2070 & 0.1614 & $0.0050^{* * *}$ & 0.1175 & 0.2110 & 0.0998 & $0.0042^{* * *}$ & 0.0886 & 0.1209 \\
\hline $\log 1 \mathrm{k}$ & -2710.0 & & & & -2666.3 & & & & -1423.3 & & & \\
\hline $\operatorname{Corr}\left(r, r^{\prime}\right.$ in $\left.\{1,2\}\right)$ & 0.0545 & $0.0107^{* * * *}$ & 0.0472 & 0.0616 & 0.0039 & $0.0008^{* * *}$ & 0.0035 & 0.0046 & 0.0069 & $0.0016^{* * * *}$ & 0.0045 & 0.0132 \\
\hline $\operatorname{Corr}\left(r, r^{\prime}\right.$ in $\left.\{3,4\}\right)$ & 0.0493 & $0.0096^{* * *}$ & 0.0413 & 0.0571 & 0.0026 & $0.0003^{* * *}$ & 0.0023 & 0.0031 & 0.0016 & $0.0004^{* * *}$ & 0.0009 & 0.0034 \\
\hline $\operatorname{Corr}\left(r\right.$ in $\{1,2\}, r^{\prime}$ in $\left.\{3,4\}\right)$ & 0.0492 & $0.0095^{* * * *}$ & 0.0412 & 0.0570 & 0.0026 & $0.0015^{*}$ & 0.0023 & 0.0031 & 0.0016 & $0.0004^{* * * *}$ & 0.0009 & 0.0034 \\
\hline Observations & 5408 & & & & 5408 & & & & 5408 & & & \\
\hline Banks & 52 & & & & 52 & & & & 52 & & & \\
\hline Periods & 26 & & & & 26 & & & & 26 & & & \\
\hline
\end{tabular}

Note. (i) The specification (a) uses fixed effects $f$ for each risk class and i.i.d. common latent factors $(F=0)$, specification (b) adds $\mathrm{AR}(1)$ dynamics to the common latent factors $(-1<F<1)$ and specification (c) considers again i.i.d. common latent factors and adds bank fixed effects, two and three quarter lags of annual GDP growth $(\triangle G D P \%)$ and the interbank rate (Euribor) together with the one year lag of the interest rate of bank $j$ on loans of class $r\left(r_{j r t-4}\right)$ as exogenous explanatory variables. The standard errors are calculated with the QML formula in equation (14) and confidence intervals, p5(BS) and p95(BS), are derived with bootstrap sampling across the cross sectional dimension $j$.

(ii) Significant coefficients with QML standard errors at the $10 \%(5 \%, 1 \%)$ are marked with $\left.{ }^{* * *},{ }^{* *}\right)$. 
Figure 1 - Probability of Default (Average)

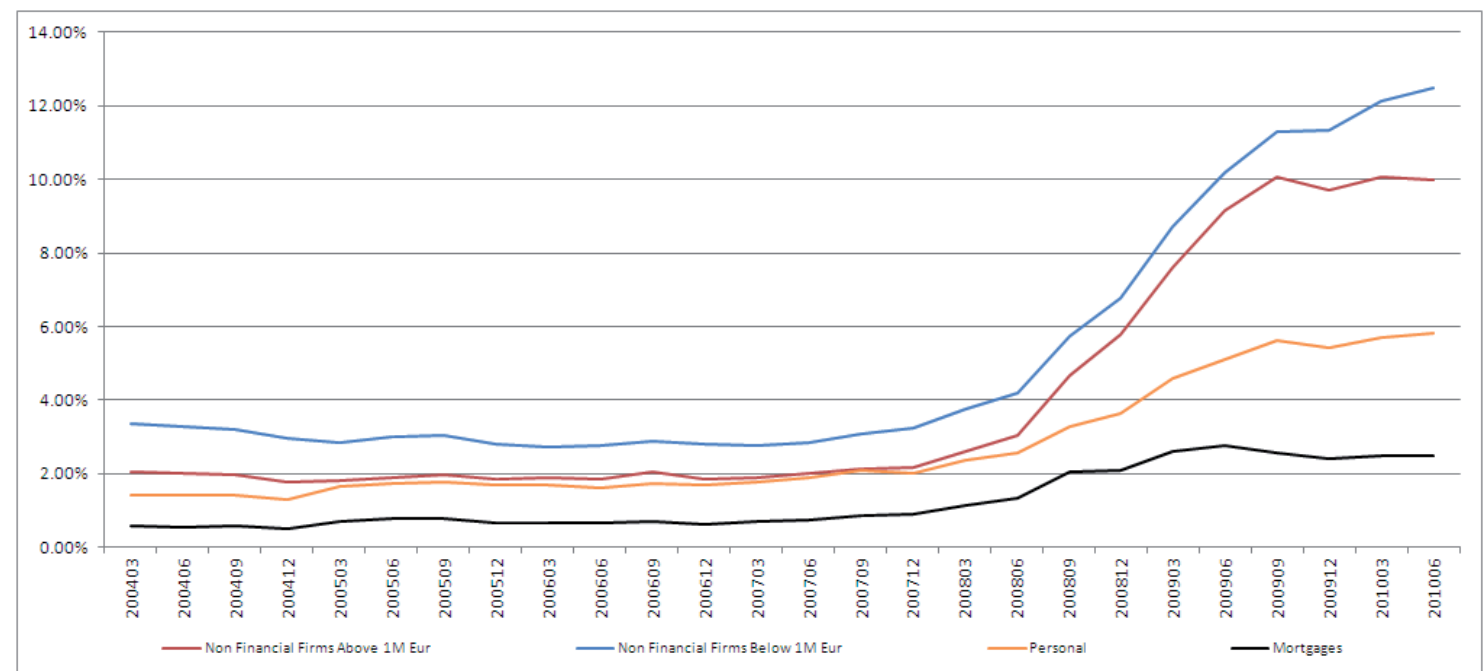

Note. This figure plots the at the end of each quarter in the sample period the crosssectional average of the probability of default for each of the risk classes of loan contracts: loans to non financial firms above 1 million euros, loans to non financial firms below 1 million euros, mortgages and personal loans. Loans to non financial firms of all sizes include exposures to real estate development and construction firms.

Figure 2 - Probability of Default (Coefficient of Variation)

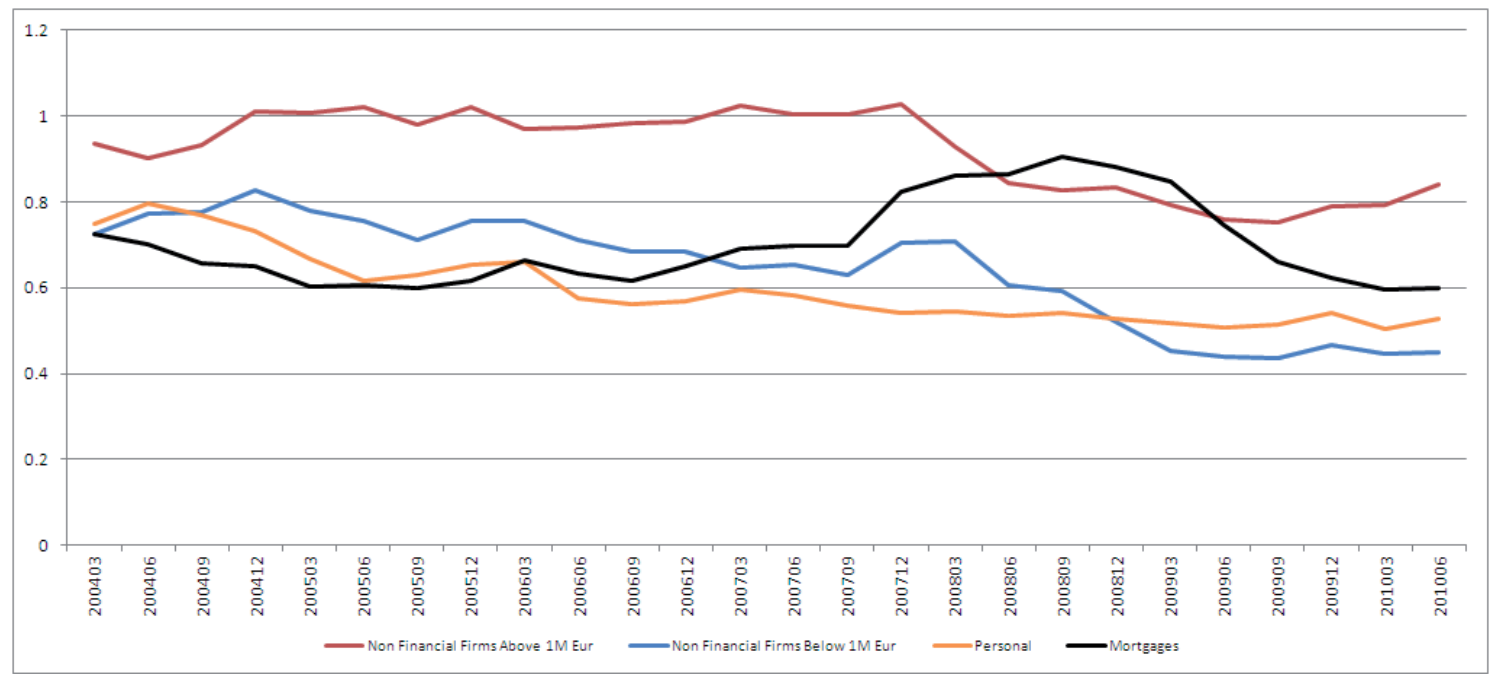

Note. This figure plots the at the end of each quarter in the sample period the crosssectional coefficient of variation of the probability of default for each of the risk classes of loan contracts: loans to non financial firms above 1 million euros, loans to non financial firms below 1 million euros, mortgages and personal loans. Loans to non financial firms of all sizes include exposures to real estate development and construction firms. 


\section{Figure 3 - Probability of Default (Cross Sectional Distribution)}
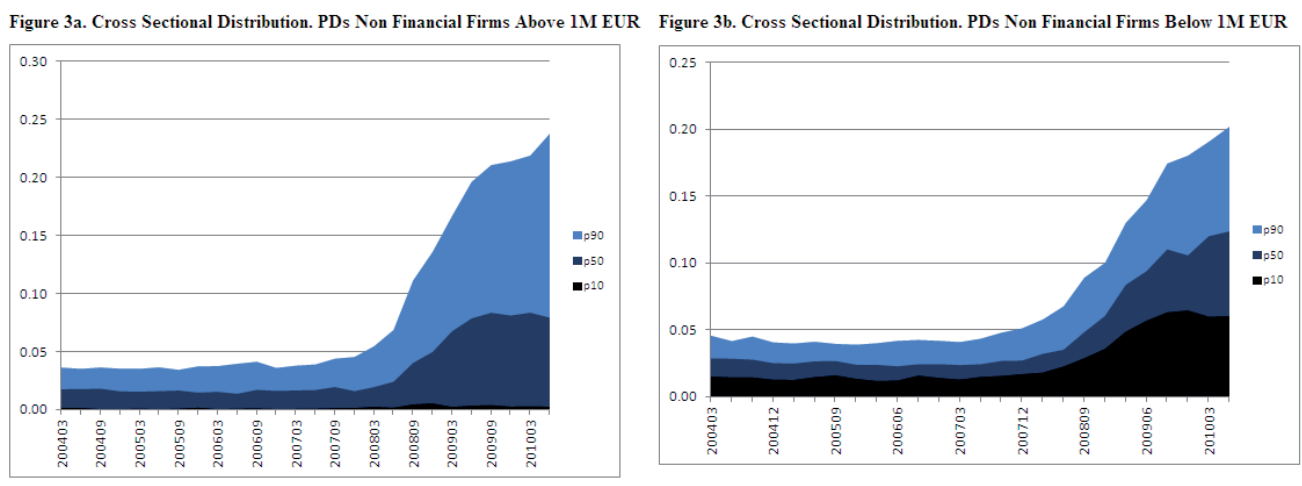

Figure 3c. Cross Sectional Distribution. PDs Personal

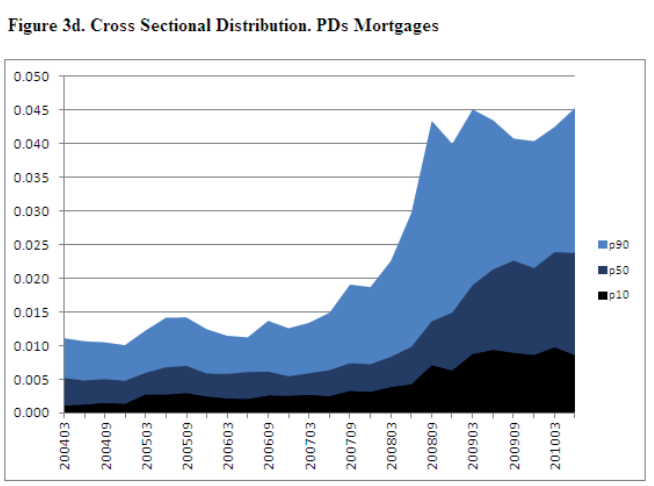

Note. This figure plots at the end of each quarter in the sample period the $10^{\text {th }}, 50^{\text {th }}$ and $90^{\text {th }}$ percentiles (p10, p50, p90) in the cross-sectional distribution of the probability of default for each of the risk classes of loan contracts: loans to non financial firms above 1 million euros, loans to non financial firms below 1 million euros, mortgages and personal loans. Loans to non financial firms of all sizes include exposures to real estate development and construction firms. 
Figure 4a. Non Financial Firms Above 1M EUR

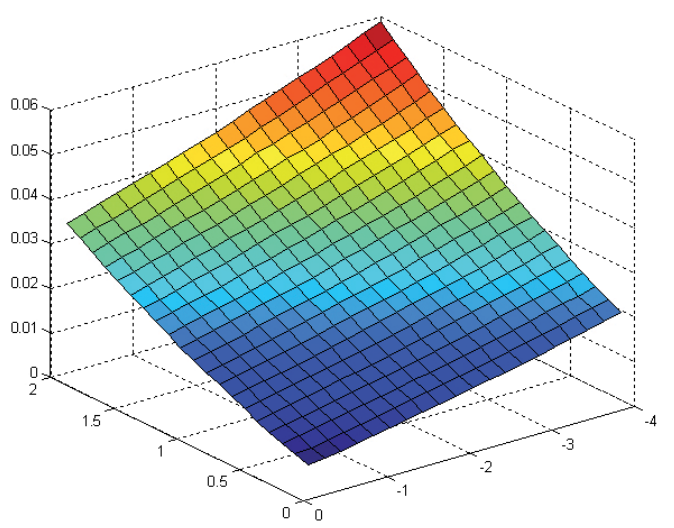

Figure 4c. Personal Loans

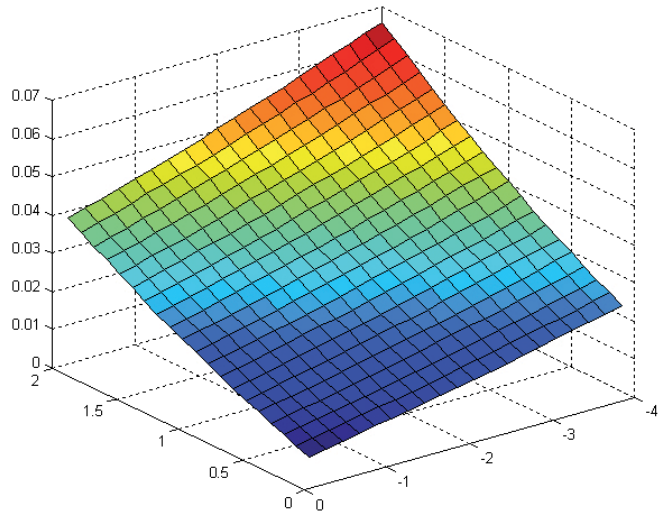

Figure 4b.Non Financial Firms Below 1M EUR

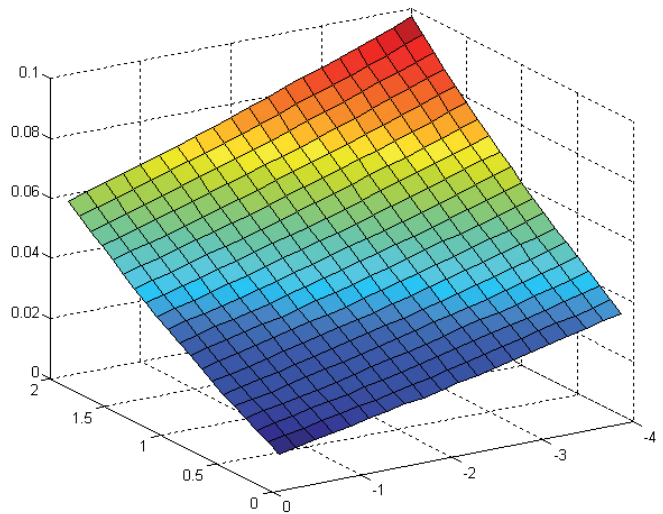

Figure 4d. Mortgages

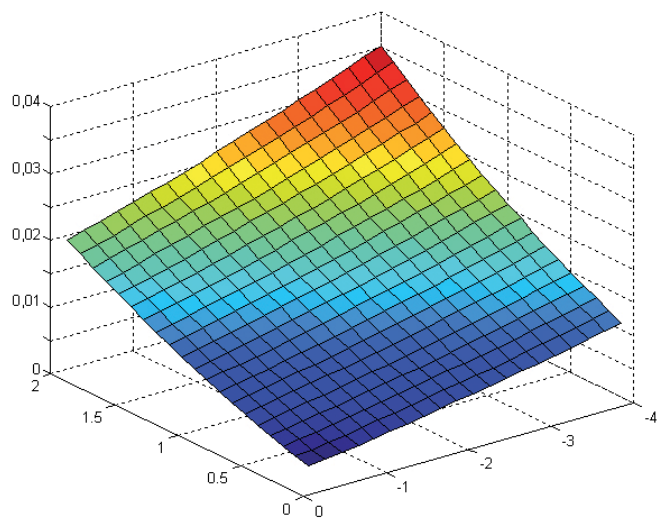

Note. This figure plots for each of the risk classes of loan contracts the variation in the average probability of default in a quarter when moving from a central scenario (GDP growth, Euribor 12 months and bank level loan rates equal to their time averages for the period 2004-2010) to an adverse scenario (shocks to GDP growth in the range $[0,-4 \%]$ and shocks to the Euribor 12 months in the range [0,2\%]). Additionally, the common latent factor switches from mean value $\left(\xi_{t}=0\right)$ in the central scenario to the adverse $1 \%$ percentile $\left(\xi_{t}=-2.3\right)$ in the adverse scenario.

The variation in the probability of default is calculated with equation (1) and presented in the vertical axis in the $[0,1]$ scale, the scenario deviations from average GDP growth and average Euribor 12 months are respectively presented on the right and left horizontal axis. 


\section{Figure 5 - Impact of Individual Bank Loan Rates on Default Rates}
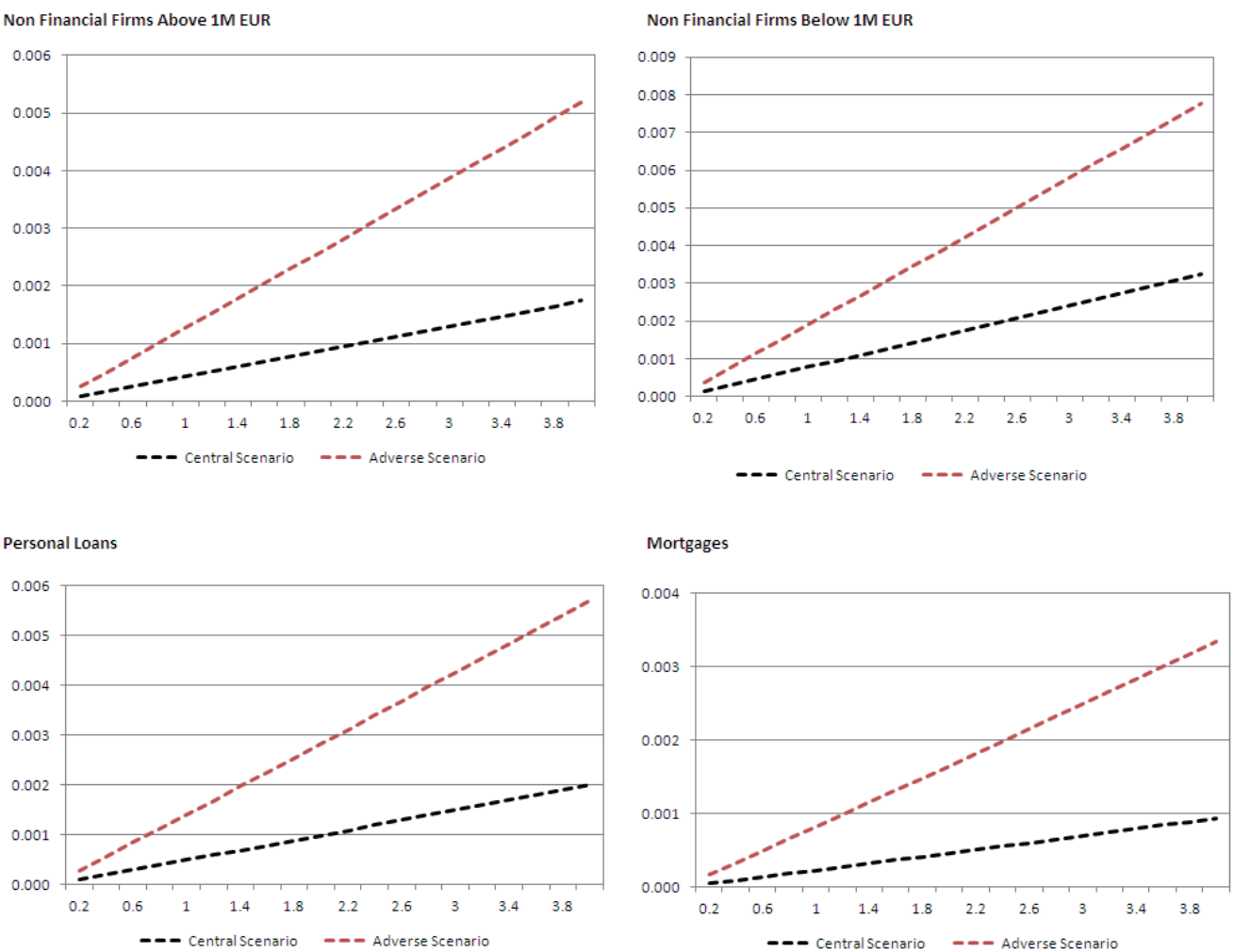

Note. This figure plots for each of the risk classes of loan contracts the variation in the average probability of default in a quarter as response to increases in the individual loan rates above their average levels for the period 2004-2010. The variation of default rates is calculated both for a central scenario (GDP growth, Euribor 12 months and bank level loan rates equal to their time averages for the period 2004-2010) and an adverse scenario (GDP growth and Euribor 12 months are respectively four percentage points below and two percentage points above period average). Additionally, the common latent factor switches from mean value $\left(\xi_{t}=0\right)$ in the central scenario to the adverse $1 \%$ percentile $\left(\xi_{t}=-2.3\right)$ in the adverse scenario.

The variation in the probability of default is calculated with equation (1) and presented in the vertical axis in the $[0,1]$ scale, the paralell increments in the bank level loan rates are presented in the horizontal axis. 
BANCO DE ESPAÑA PUBLICATIONS

\author{
WORKING PAPERS
}

1201 CARLOS PÉREZ MONTES: Regulatory bias in the price structure of local telephone services.

1202 MAXIMO CAMACHO, GABRIEL PEREZ-QUIROS and PILAR PONCELA: Extracting non-linear signals from several economic indicators.

1203 MARCOS DAL BIANCO, MAXIMO CAMACHO and GABRIEL PEREZ-QUIROS: Short-run forecasting of the euro-dollar exchange rate with economic fundamentals.

1204 ROCIO ALVAREZ, MAXIMO CAMACHO and GABRIEL PEREZ-QUIROS: Finite sample performance of small versus large scale dynamic factor models.

1205 MAXIMO CAMACHO, GABRIEL PEREZ-QUIROS and PILAR PONCELA: Markov-switching dynamic factor models in real time.

1206 IGNACIO HERNANDO and ERNESTO VILLANUEVA: The recent slowdown of bank lending in Spain: are supply-side factors relevant?

1207 JAMES COSTAIN and BEATRIZ DE BLAS: Smoothing shocks and balancing budgets in a currency union.

1208 AITOR LACUESTA, SERGIO PUENTE and ERNESTO VILLANUEVA: The schooling response to a sustained Increase in low-skill wages: evidence from Spain 1989-2009.

1209 GABOR PULA and DANIEL SANTABÁRBARA: Is China climbing up the quality ladder?

1210 ROBERTO BLANCO and RICARDO GIMENO: Determinants of default ratios in the segment of loans to households in Spain.

1211 ENRIQUE ALBEROLA, AITOR ERCE and JOSÉ MARÍA SERENA: International reserves and gross capital flows. Dynamics during financial stress.

1212 GIANCARLO CORSETTI, LUCA DEDOLA and FRANCESCA VIANI: The international risk-sharing puzzle is at businesscycle and lower frequency.

1213 FRANCISCO ALVAREZ-CUADRADO, JOSE MARIA CASADO, JOSE MARIA LABEAGA and DHANOOS SUTTHIPHISAL: Envy and habits: panel data estimates of interdependent preferences.

1214 JOSE MARIA CASADO: Consumption partial insurance of Spanish households.

1215 J. ANDRÉS, J. E. BOSCÁ and J. FERRI: Household leverage and fiscal multipliers.

1216 JAMES COSTAIN and BEATRIZ DE BLAS: The role of fiscal delegation in a monetary union: a survey of the political economy issues.

1217 ARTURO MACÍAS and MARIANO MATILLA-GARCÍA: Net energy analysis in a Ramsey-Hotelling growth model.

1218 ALFREDO MARTÍN-OLIVER, SONIA RUANO and VICENTE SALAS-FUMÁS: Effects of equity capital on the interest rate and the demand for credit. Empirical evidence from Spanish banks.

1219 PALOMA LÓPEZ-GARCÍA, JOSÉ MANUEL MONTERO and ENRIQUE MORAL-BENITO: Business cycles and investment in intangibles: evidence from Spanish firms.

1220 ENRIQUE ALBEROLA, LUIS MOLINA and PEDRO DEL RÍO: Boom-bust cycles, imbalances and discipline in Europe.

1221 CARLOS GONZÁLEZ-AGUADO and ENRIQUE MORAL-BENITO: Determinants of corporate default: a BMA approach.

1222 GALO NUÑO and CARLOS THOMAS: Bank leverage cycles.

1223 YUNUS AKSOY and HENRIQUE S. BASSO: Liquidity, term spreads and monetary policy.

1224 FRANCISCO DE CASTRO and DANIEL GARROTE: The effects of fiscal shocks on the exchange rate in the EMU and differences with the US.

1225 STÉPHANE BONHOMME and LAURA HOSPIDO: The cycle of earnings inequality: evidence from Spanish social security data.

1226 CARMEN BROTO: The effectiveness of forex interventions in four Latin American countries.

1227 LORENZO RICCI and DAVID VEREDAS: TailCoR.

1228 YVES DOMINICY, SIEGFRIED HÖRMANN, HIROAKI OGATA and DAVID VEREDAS: Marginal quantiles for stationary processes.

1229 MATTEO BARIGOZZI, ROXANA HALBLEIB and DAVID VEREDAS: Which model to match?

1230 MATTEO LUCIANI and DAVID VEREDAS: A model for vast panels of volatilities.

1231 AITOR ERCE: Does the IMF's official support affect sovereign bond maturities?

1232 JAVIER MENCÍA and ENRIQUE SENTANA: Valuation of VIX derivatives. 
1233 ROSSANA MEROLA and JAVIER J. PÉREZ: Fiscal forecast errors: governments vs independent agencies?

1234 MIGUEL GARCÍA-POSADA and JUAN S. MORA-SANGUINETTI: Why do Spanish firms rarely use the bankruptcy system? The role of the mortgage institution.

1235 MAXIMO CAMACHO, YULIYA LOVCHA and GABRIEL PEREZ-QUIROS: Can we use seasonally adjusted indicators in dynamic factor models?

1236 JENS HAGENDORFF, MARÍA J. NIETO and LARRY D. WALL: The safety and soundness effects of bank M\&As in the EU: Does prudential regulation have any impact?

1237 SOFÍA GALÁN and SERGIO PUENTE: Minimum wages: do they really hurt young people?

1238 CRISTIANO CANTORE, FILIPPO FERRONI and MIGUEL A. LEÓN-LEDESMA: The dynamics of hours worked and technology.

1239 ALFREDO MARTÍN-OLIVER, SONIA RUANO and VICENTE SALAS-FUMÁS: Why did high productivity growth of banks precede the financial crisis?

1240 MARIA DOLORES GADEA RIVAS and GABRIEL PEREZ-QUIROS: The failure to predict the Great Recession. The failure of academic economics? A view focusing on the role of credit.

1241 MATTEO CICCARELLI, EVA ORTEGA and MARIA TERESA VALDERRAMA: Heterogeneity and cross-country spillovers in macroeconomic-financial linkages.

1242 GIANCARLO CORSETTI, LUCA DEDOLA and FRANCESCA VIANI: Traded and nontraded goods prices, and international risk sharing: an empirical investigation.

1243 ENRIQUE MORAL-BENITO: Growth empirics in panel data under model uncertainty and weak exogeneity.

1301 JAMES COSTAIN and ANTON NAKOV: Logit price dynamics.

1302 MIGUEL GARCÍA-POSADA: Insolvency institutions and efficiency: the Spanish case.

1303 MIGUEL GARCÍA-POSADA and JUAN S. MORA-SANGUINETTI: Firm size and judicial efficacy: evidence for the new civil procedures in Spain.

1304 MAXIMO CAMACHO and GABRIEL PEREZ-QUIROS: Commodity prices and the business cycle in Latin America: living and dying by commodities?

1305 CARLOS PÉREZ MONTES: Estimation of regulatory credit risk models.

\begin{tabular}{|r|c|}
\hline BANCODEESPAÑA & Unidad de Servicios Auxiliares \\
Eurosistema & Alcalá, $48-28014$ Madrid \\
& Telephone +34913386368 \\
E-mail: publicaciones@bde.es \\
www.bde.es
\end{tabular}

